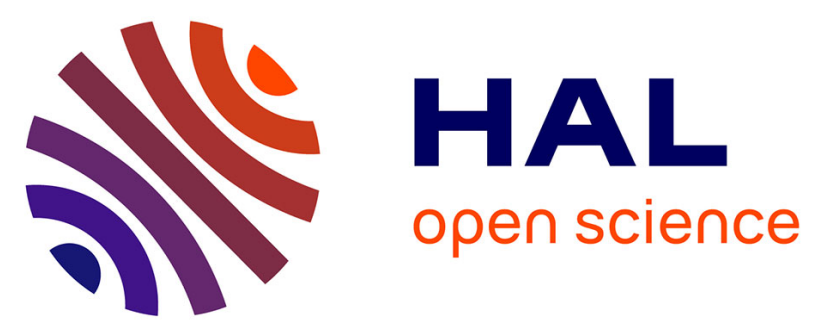

\title{
ERM-Dependent Assembly of T Cell Receptor Signaling and Co-stimulatory Molecules on Microvilli prior to Activation
}

Shirsendu Ghosh, Vincenzo Di Bartolo, Liron Tubul, Eyal Shimoni, Elena Kartvelishvily, Tali Dadosh, Sara W. Feigelson, Ronen Alon, Andres Alcover, Gilad Haran

\section{To cite this version:}

Shirsendu Ghosh, Vincenzo Di Bartolo, Liron Tubul, Eyal Shimoni, Elena Kartvelishvily, et al.. ERMDependent Assembly of T Cell Receptor Signaling and Co-stimulatory Molecules on Microvilli prior to Activation. Cell Reports, 2020, 30 (10), pp.3434-3447.e6. 10.1016/j.celrep.2020.02.069 . pasteur03258643

\section{HAL Id: pasteur-03258643}

\section{https://hal-pasteur.archives-ouvertes.fr/pasteur-03258643}

Submitted on 11 Jun 2021

HAL is a multi-disciplinary open access archive for the deposit and dissemination of scientific research documents, whether they are published or not. The documents may come from teaching and research institutions in France or abroad, or from public or private research centers.
L'archive ouverte pluridisciplinaire HAL, est destinée au dépôt et à la diffusion de documents scientifiques de niveau recherche, publiés ou non, émanant des établissements d'enseignement et de recherche français ou étrangers, des laboratoires publics ou privés. 


\section{Cell Reports}

\section{ERM-Dependent Assembly of T Cell Receptor Signaling and Co-stimulatory Molecules on Microvilli prior to Activation}

\section{Graphical Abstract}

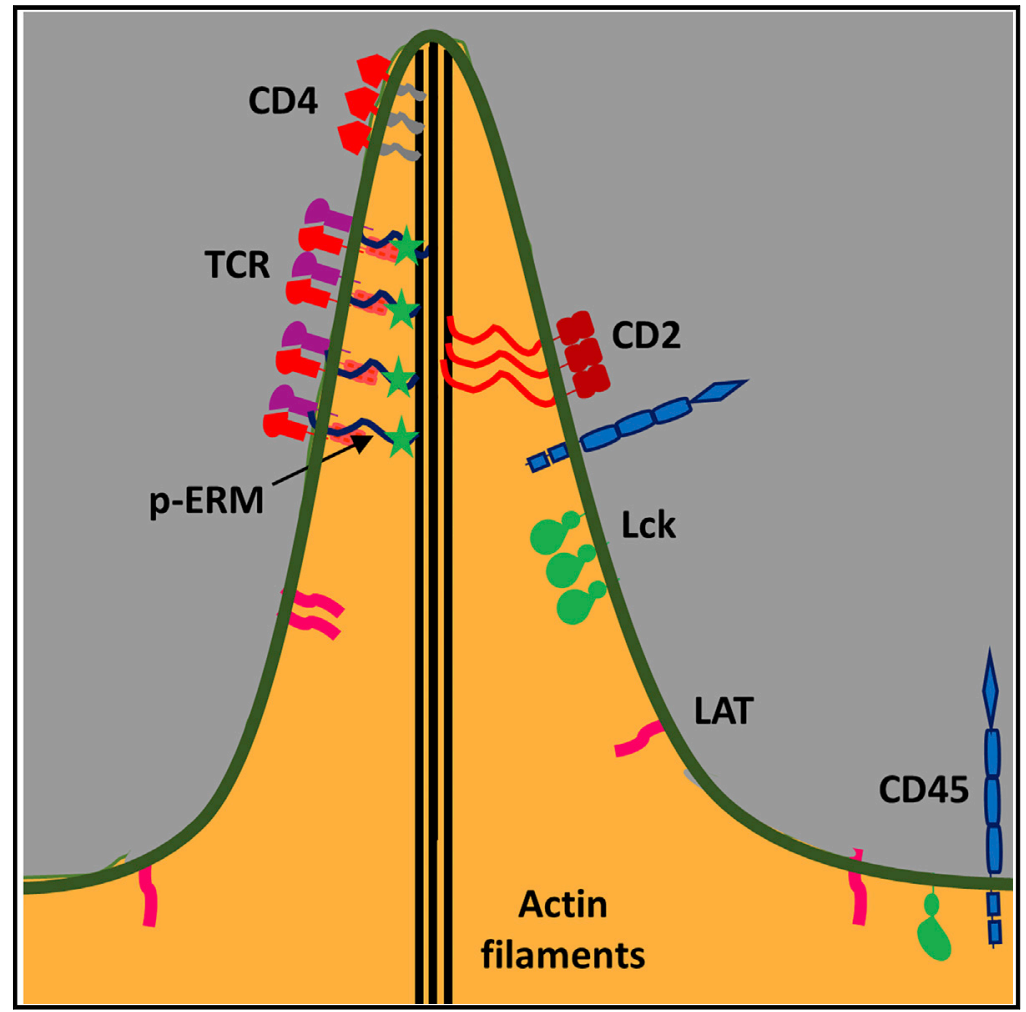

Highlights

- Single-molecule microscopy maps signaling molecules on the resting $T$ cell membrane

- TCR $\alpha \beta$, TCR $\zeta$, CD4, CD2, Lck, and LAT are all highly enriched on microvilli

- TCR localization is mediated by ERM proteins

- Microvilli are hubs for TCR signaling, facilitating fast initial immune response

\section{Authors}

Shirsendu Ghosh, Vincenzo Di Bartolo, Liron Tubul, ..., Ronen Alon, Andres Alcover, Gilad Haran

\section{Correspondence}

shirsendu.ghosh@weizmann.ac.il (S.G.), gilad.haran@weizmann.ac.il (G.H.)

\section{In Brief}

T-cell surfaces are covered with microvilli, actin-rich and flexible protrusions. Ghosh et al. show that T cell receptor complex molecules, as well as several proximal signaling molecules, are preassembled on microvilli in an ERMdependent manner. These results establish microvilli as key signaling hubs that facilitate initial antigen sensing by $T$ cells. 


\title{
ERM-Dependent Assembly of T Cell Receptor Signaling and Co-stimulatory Molecules on Microvilli prior to Activation
}

\author{
Shirsendu Ghosh, ${ }^{1,5, *}$ Vincenzo Di Bartolo, ${ }^{2}$ Liron Tubul, ${ }^{1}$ Eyal Shimoni, ${ }^{3}$ Elena Kartvelishvily, ${ }^{3}$ Tali Dadosh, ${ }^{3}$ \\ Sara W. Feigelson, ${ }^{4}$ Ronen Alon, ${ }^{4}$ Andres Alcover, ${ }^{2}$ and Gilad Haran ${ }^{1, *}$ \\ ${ }^{1}$ Department of Chemical and Biological Physics, Weizmann Institute of Science, Rehovot 7610001, Israel \\ 'Lymphocyte Cell Biology Unit, INSERM U1221, Department of Immunology, Institut Pasteur, Paris 75015, France \\ ${ }^{3}$ Chemical Research Support, Weizmann Institute of Science, Rehovot 7610001, Israel \\ ${ }^{4}$ Department of Immunology, Weizmann Institute of Science, Rehovot 7610001, Israel \\ ${ }^{5}$ Lead Contact \\ *Correspondence: shirsendu.ghosh@weizmann.ac.il (S.G.), gilad.haran@weizmann.ac.il (G.H.) \\ https://doi.org/10.1016/j.celrep.2020.02.069
}

\section{SUMMARY}

T cell surfaces are covered with microvilli, actin-rich and flexible protrusions. We use super-resolution microscopy to show that $\geq 90 \%$ of T cell receptor (TCR) complex molecules TCR $\alpha \beta$ and TCR $\zeta$, as well as the co-receptor CD4 (cluster of differentiation 4) and the co-stimulatory molecule CD2, reside on microvilli of resting human T cells. Furthermore, TCR proximal signaling molecules involved in the initial stages of the immune response, including the protein tyrosine kinase Lck (lymphocyte-specific protein tyrosine kinase) and the key adaptor LAT (linker for activation of $T$ cells), are also enriched on microvilli. Notably, phosphorylated proteins of the ERM (ezrin, radixin, and moesin) family colocalize with TCR $\alpha \beta$ as well as with actin filaments, implying a role for one or more ERMs in linking the TCR complex to the actin cytoskeleton within microvilli. Our results establish microvilli as key signaling hubs, in which the TCR complex and its proximal signaling molecules and adaptors are preassembled prior to activation in an ERM-dependent manner, facilitating initial antigen sensing.

\section{INTRODUCTION}

T cells play a pivotal role in adaptive immunity. When encountering antigen-presenting cells (APCs), T cells undergo a major reorganization of their surface, with a subset of these encounters leading to the formation of immunological synapses (ISs) (Dustin, 2014; Grakoui et al., 1999; Monks et al., 1998). Recent evidence suggests that within seconds of T cell receptor (TCR) occupancy by cognate antigenic peptides, the TCR complex transmits T cell activation signals in the form of phosphorylation and calcium mobilization (Friedl and Bröcker, 2002; Henrickson et al., 2013; Marangoni et al., 2013). These signals are often generated by T cells that engage their APCs for minutes and even shorter times (Friedl and Bröcker, 2002; Henrickson et al., 2013; Marangoni et al., 2013). These observations suggest that most TCR signaling events occur during brief contacts between the T cell and various APCs. How such short-lived contacts transmit $T$ cell activation signals so efficiently remains an enigma. The TCR complex (composed of the transmembrane proteins $\mathrm{TCR} \alpha \beta, \mathrm{CD} 3 \gamma, \delta, \varepsilon$, and TCR $\zeta_{\text {) }}$ initiates the $\mathrm{T}$ cell immune response after it recognizes foreign-antigen-derived peptides bound to major histocompatibility complex (MHC) molecules on the surface of APCs. The roles of the TCR co-receptors CD4 (cluster of differentiation 4) or CD8, adhesion and cosignaling receptors like CD2, and proximal signaling proteins such as the protein tyrosine kinase Lck (lymphocyte-specific protein tyrosine kinase), the adaptor LAT (linker for activation of $T$ cells), and the tyrosine phosphatase CD45 are well described (Dustin, 2014; Kaizuka et al., 2009; Malissen and Bongrand, 2015; Monks et al., 1998). However, how these molecules participate in translating the very initial TCR ligand occupancy events to productive TCR signaling is still poorly understood. Furthermore, while the involvement of multiple cytoskeletal elements in the formation of the IS has been documented (Jung et al., 2016; Klammt and Lillemeier, 2012; Lasserre et al., 2010; Razvag et al., 2018; Roumier et al., 2001), the role of cytoskeletal components in the initial antigen recognition events triggering TCR signaling remains unclear. While several T-cell-related or more general models were proposed to explain protein distribution on cellular surfaces, (Davis and van der Merwe, 2006; Lillemeier et al., 2010; Roh et al., 2015; Sezgin et al., 2017; Simons and Sampaio, 2011), much remains to be learned about the organization of key surface receptors implicated in T-cell activation and the formation of functional immune synapses.

Recent advances in imaging techniques, such as fluorescence super-resolution microscopy, have led to the observation that different membrane receptors indeed exist as nanoclusters of an average size of a few tens to hundreds of nanometers even in nonactivated T cells. For example, Davis and co-workers suggested that in resting murine T cells, two very important TCR signaling proteins, TCR $\zeta$ and LAT, pre-cluster into separate protein islands on the T cell membrane (Lillemeier et al., 2010). They also showed that in murine T cells, the co-receptor CD4 forms distinct nanoclusters (Roh et al., 2015). Using confocal, total internal reflection fluorescence (TIRF), and super-resolution 
microscopy, Ritter et al. (2017) unraveled the role of dynamic regulation of the cortical actin cytoskeleton in initiation and termination of secretion of "lytic granules." Samelson and coworkers reported that the kinase ZAP-70 co-localizes with TCR , while both partially mix with LAT molecules in human lymphocytes and Jurkat T cells (Sherman et al., 2011). Gaus and coworkers showed that the active conformation of the key TCR associated kinase Lck promotes its clustering on the membrane of Jurkat cells, whereas the inactive conformation of this kinase hinders its clustering (Rossy et al., 2013). They also showed that $T$ cell signaling initiation occurs only within dense clusters of TCR-CD3 complexes in Jurkat T cells (Pageon et al., 2016). Finally, Lillemeier and coworkers demonstrated nanometerscale clustering of TCR molecules on T cells in resting lymph nodes of mice (Hu et al., 2016).

Strikingly, all of these studies considered the T cell membrane as a two-dimensional (2D) sheet and ignored the complex 3D microvillar structures on the surface of $\mathrm{T}$ cells (Majstoravich et al., 2004; Nijhara et al., 2004; Schwarz and Alon, 2004). These finger-like protrusions, $\sim 100 \mathrm{~nm}$ in diameter and a few hundreds of nanometers in length, are highly flexible and dynamic. We recently discovered that in human peripheral blood $T$ cells and in effector $T$ lymphocytes differentiated from these lymphocytes, TCR $\alpha \beta$ molecules are preferentially localized to microvilli, suggesting a role for these dynamic protrusions in initial T cell recognition of cognate antigenic peptides presented by dendritic cells and other APCs (Jung et al., 2016). Indeed, Krummel and coworkers demonstrated that microvilli function as sensors that scan the surface of encountered APCs within seconds (Cai et al., 2017). Sherman and co-workers also observed that microvilli are involved in early T cell activation (Razvag et al., 2018), and Jun and coworkers demonstrated that upon TCR activation $T$ cells release nanoscale microvilli-related vesicles that interact with APCs and transfer cargo to these cells through a process termed trogocytosis (Kim et al., 2018).

Although these recent studies invoked a key role for microvilli in the ability of $\mathrm{T}$ cells to encounter antigenic peptides, they did not resolve how TCR-associated signaling molecules, which must operate shortly after the initial occupancy with a ligand, get rapidly recruited by stimulated TCR complexes. To shed light on this issue, we study here the distribution of key TCR signaling components both on human $\mathrm{T}$ effector cells and on Jurkat T cells, a prototype CD4 T cell line (Goodfellow et al., 2015). We find that apart from CD45, all of these molecules are presegregated on the microvilli of both types of T cells. We further determine the mechanism of this unique enrichment of TCR signaling machineries on microvilli by interfering with their anchorage to the dense cortical actin cytoskeleton of the microvilli. Our work establishes microvilli as important hubs for TCR signaling on which all key molecular players required for the initial T cell-APC interaction are pre-organized.

\section{RESULTS}

Mapping the Distribution of Membrane Proteins in Relation to Microvilli

We previously demonstrated that a combination of variableangle total internal reflection microscopy (VA-TIRFM) and sto- chastic localization nanoscopy (SLN) can map the distribution of peripheral blood human $\mathrm{T}$ cell surface proteins with respect to microvilli (Jung et al., 2016). Here, we adopted the same methodology to study a large set of membrane proteins on the surface of resting, human effector T cells (Figure 1A) as well as non-stimulated Jurkat cells (Figure 1B). Each membrane protein of interest on the cells was labeled with an Alexa-Fluor-647-tagged antibody. The cells were then fixed and stained with the dye FM143FX. A home-built TIRF microscope was used to image the cells, which were placed on a poly-L-lysine (PLL)-coated surface (Figures 1C-1E). Since the cells were already fixed, the interaction with the PLL surface did not cause any distortion of their topography (STAR Methods; Figure S1), as directly verified by scanning electron microscopy (SEM) (Figure 1A-B). Initially, VA-TIRFM images were obtained from treated cells residing on a glass surface. The fluorescence intensity measured at each point in an image was converted into the distance of that point from the glass ( $\delta z$ ) (Stock et al., 2003; Sundd et al., 2010). The set of $\delta z$ values obtained from VA-TIRFM images permitted us to plot a map of the membrane structure, thus obtaining the 3D membrane topography (Figures $1 \mathrm{~F}$ and $1 \mathrm{G}$ ). By combining measurements at several angles of incidence of the excitation beam, we improved the statistical precision of the procedure (Figures S1A-S1H).

The typical width of microvilli, as observed in SEM images (Figures $1 \mathrm{~A}$ and $1 \mathrm{~B}$ ), is $100 \mathrm{~nm}$ or less. This is clearly below the optical diffraction limit, and hence microvilli would appear thicker than in reality by any imaging technique that is not able to break this limit. TIRFM can obtain sub-diffraction resolution only in the $Z$ direction but is diffraction limited in the $X-Y$ plane, and this is why the microvilli appear thicker in our TIRF images than in SEM images (Figure S1I). Nevertheless, the density of microvilli calculated from segmentation maps of VA-TIRFM images compared well with the density obtained from SEM images (Figures $\mathrm{S} 1 \mathrm{~A}-\mathrm{S} 1 \mathrm{H}$ ), indicating that the method did not miss a significant number of microvilli due to the lower $X-Y$ resolution. As an additional means for the assignment of observed structures as microvilli (especially elongated structures classified as microvilli lying horizontally), we performed L-selectin localization experiments (STAR Methods; Figures S1J-S1L).

We used SLN to obtain maps of antibody-labeled membrane proteins of interest. In SLN, the location of single emitters is determined with accuracy well below the diffraction limit (Endesfelder and Heilemann, 2015; Rust et al., 2006; van de Linde et al., 2011). By superimposing the super-resolved membrane protein map on the 3D membrane topographical map, we were able to characterize the distribution of each protein molecule in relation to microvilli. We collected super-resolution images from two separate planes of each cell, right at the interface with the glass substrate (where mostly microvillar regions and a small fraction of cell body regions were observed, $0 \mathrm{~nm}$ plane) and $400 \mathrm{~nm}$ away from the substrate (where both microvilli and cell body regions were imaged, $-400 \mathrm{~nm}$ plane). The intensity of evanescent field decreases exponentially, although it is high enough to detect molecules with equal probability in the $0 \mathrm{~nm}$ plane and $-400 \mathrm{~nm}$ plane. We verified this by carrying out experiments on samples in which dye molecules were randomly distributed on either plane (STAR Methods; Figures S1M-S1O). 

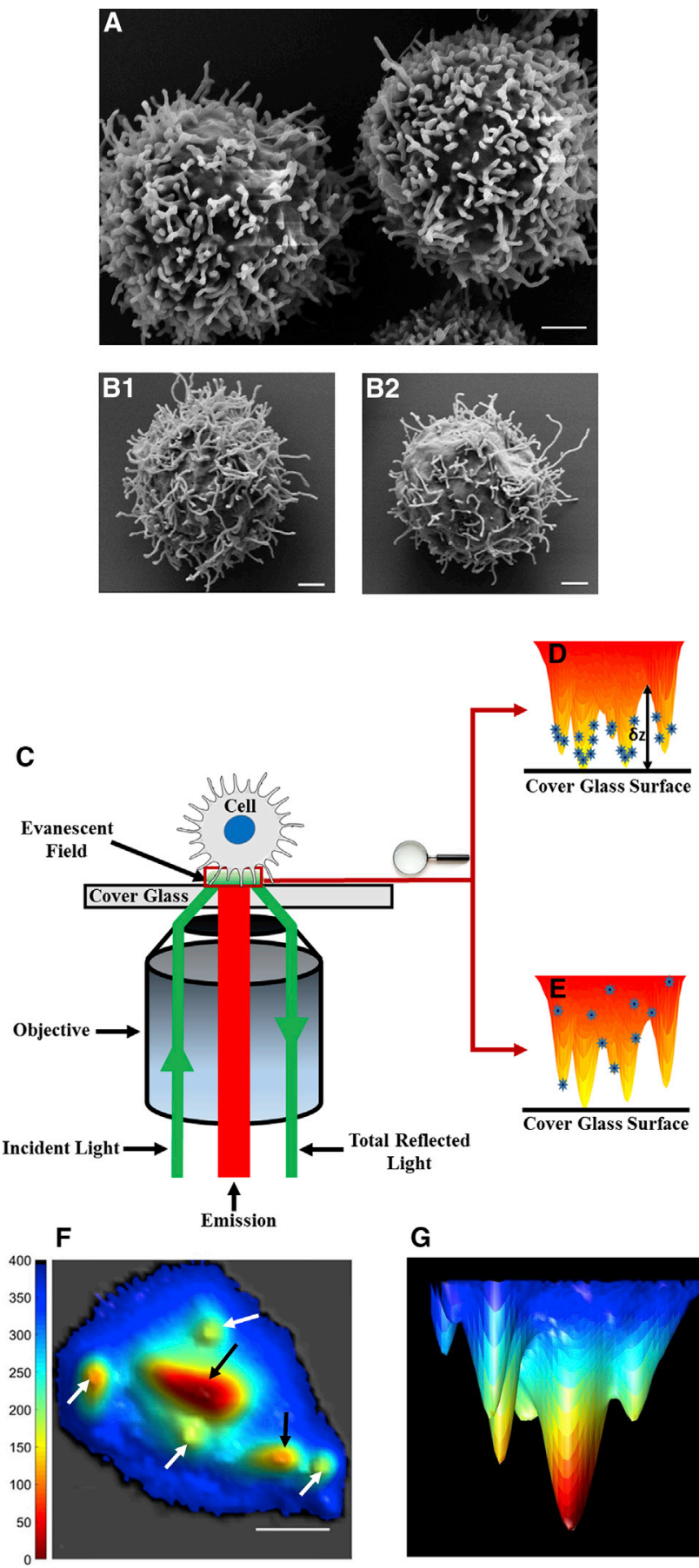

G

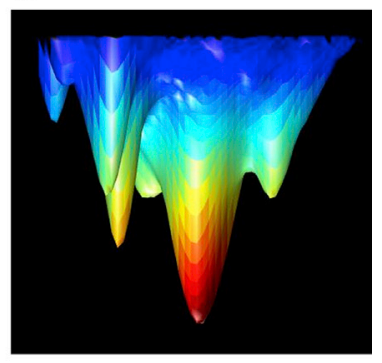

Figure 1. Combining VA-TIRFM and SLN for Localizing Molecules with Respect to Microvilli

(A and B) SEM images of $T$ cells at a magnification of 20,000x, demonstrating the dominance of microvilli on the cell surface.

(A) Human effector T cell.

(B) Two examples of Jurkat T cells. Scale bars, $1 \mu \mathrm{m}$.

(C) A schematic configuration of the TIRFM setup.

(D) Schematic of a cell with proteins on the microvilli. The distance from the glass to the surface of the cell at each point $(\delta z)$ is obtained from analysis of TIRF images measured over a range of angles of incidence.
Using the two sets of images and detailed image analysis, we segmented the membrane area of each cell into either the microvillar region or the cell-body region and then determined the distribution of each of the studied molecules in the two regions. We also quantified changes in the molecular distribution as a function of distance from the tips of microvilli (which were defined as those regions that are not more than $20 \mathrm{~nm}$ away from the pixel with the minimum $\delta z$ value). More details about our image analysis methodology are provided in STAR Methods. However, it is important to point out here that this analysis depends not on the diffraction-limited resolution of the TIRF images in the $X-Y$ plane but only on the high resolution in the $Z$ direction, which is due to the properties of the evanescent field in TIRFM. We applied this methodology to study a series of TCR-associated proteins on human effector T cells and Jurkat cells (Figure 2). These experiments are described in detail below. Statistical data on the number of cells measured in each experiment, as well as the percentage of molecules of different signaling protein localized in the microvilli, are provided in Table S1.

$\operatorname{TCR} \alpha \beta$

TCR $\alpha \beta$ is a dimer that constitutes the recognition unit of the TCR complex (Alcover et al., 2018). It combines with CD3 and TCR $\zeta$ to carry out signal transduction upon binding to peptide-antigenMHC molecules on the APC (Alcover et al., 2018). In our previous work, we showed that TCR $\alpha \beta$ molecules localize almost exclusively to the microvillar regions of human peripheral T lymphocytes (Jung et al., 2016). We now verified this finding in Jurkat $\mathrm{T}$ cells. Indeed, we observed that TCR $\alpha \beta$ molecules strongly localize to the microvillar regions of these cells as well (Figures $2 \mathrm{~A}$ and 2D). Our calculations showed that $89.0 \% \pm 2.4 \%$ of $\mathrm{TCR} \alpha \beta$ molecules reside on microvilli (Figure $2 \mathrm{M}$ ). As shown in Figure $2 \mathrm{~N}$, as the distance increases from the microvillar tip regions, the surface-normalized increase in the fraction of total $\mathrm{TCR} \alpha \beta$ molecules ( $\delta \mathrm{Count} / \delta$ Area plot) falls sharply, pointing to strong localization on the microvilli. Cluster analysis using Ripley's $\mathrm{K}$ function showed that the maximum cluster diameter of TCR $\alpha \beta$ molecules is as high as $167 \pm 21 \mathrm{~nm}$ (Figure 2O; for a brief description of the analysis, see STAR Methods). This maximum cluster size is in good agreement with the geometrical dimensions of microvilli, considering their size distribution and the fact that many of them lie partially or fully on their side.

TCR

TCR $\zeta$ (also known as CD247 or CD3ל) appears as a dimer and is essential for the formation of the TCR complex and its stability (Alcover et al., 2018). During the T cell activation process, it is phosphorylated by Lck on its ITAMs (immune receptor tyrosine-based activation motifs), which facilitates interaction with ZAP-70 (Alcover et al., 2018). We observed that, like TCR $\alpha \beta$, TCR $\zeta$ molecules reside almost exclusively on the microvilli of

(E) Schematic of a cell with proteins randomly distributed throughout the membrane.

(F) Bottom view of a representative 3D reconstruction map of a Jurkat cell membrane (white arrows indicate microvilli positioned vertically with respect to the glass surface, and black arrows indicate microvilli lying down horizontally). Scale bar, $1 \mu \mathrm{m}$.

(G) Side view of the 3D reconstruction map of the same Jurkat cell membrane shown in (F). 

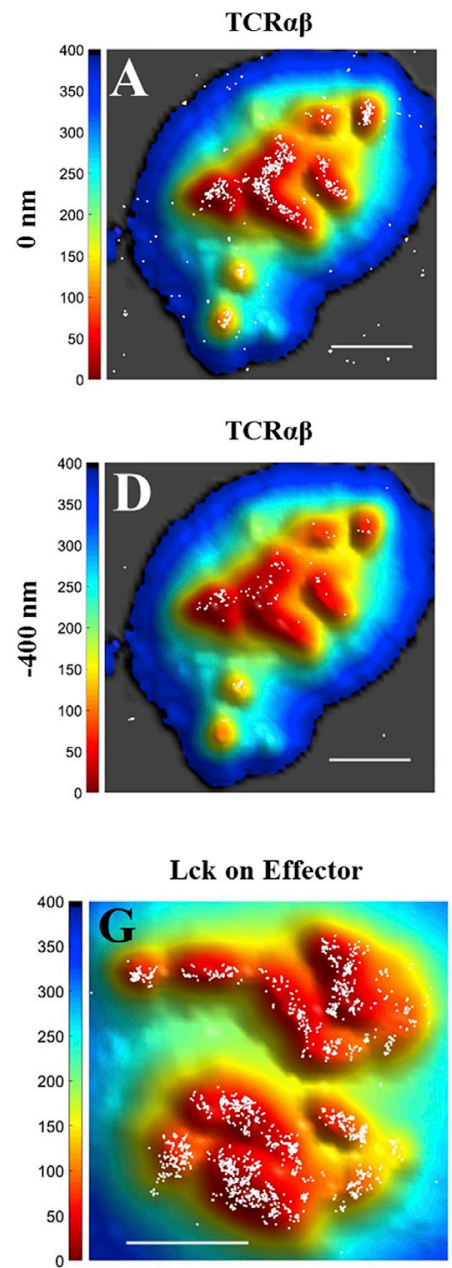

CD2 on Effector
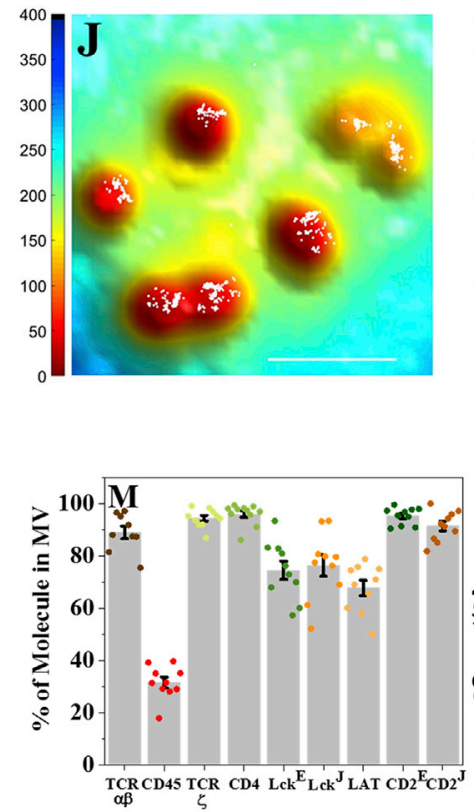

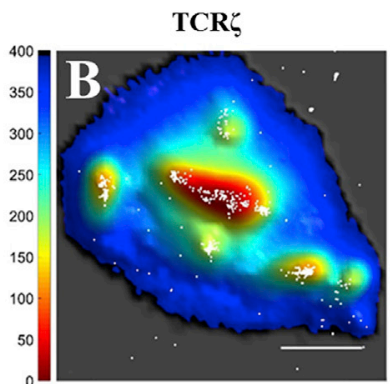

TCR $\zeta$

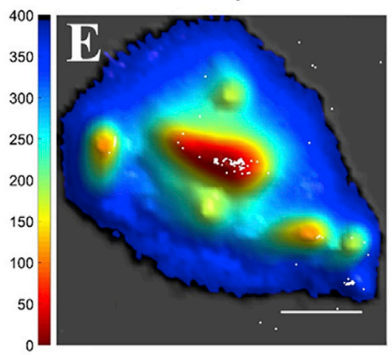

Lck on Jurkat

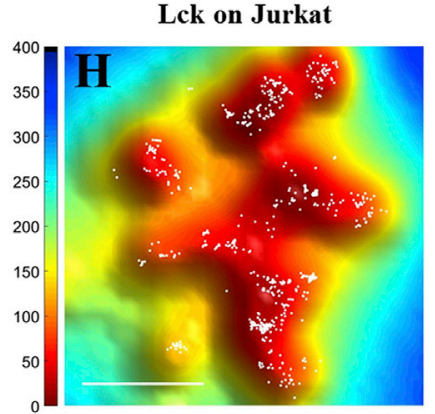

CD2 on Jurkat

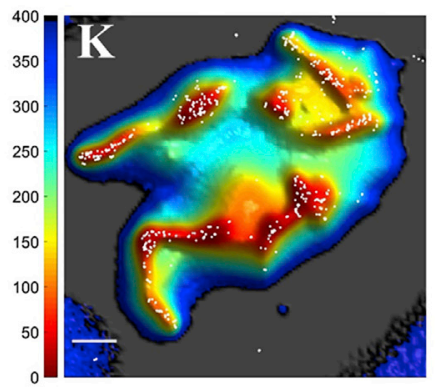

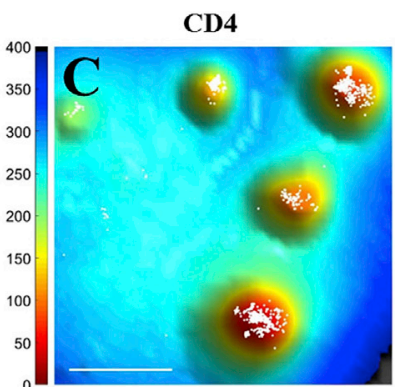

CD4

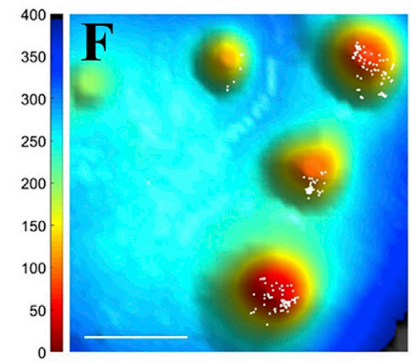

LAT on Jurkat

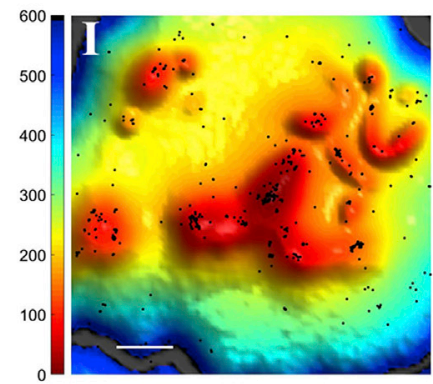

CD45 on Jurkat

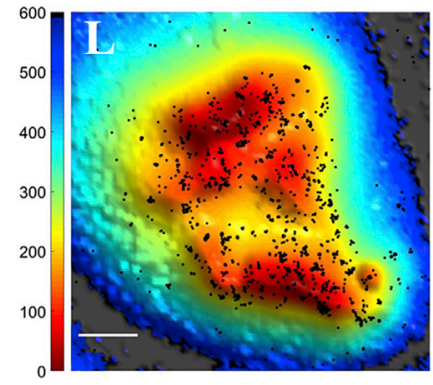

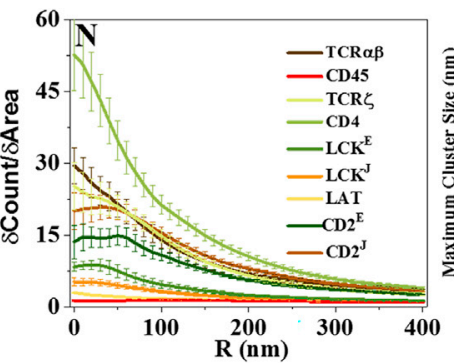

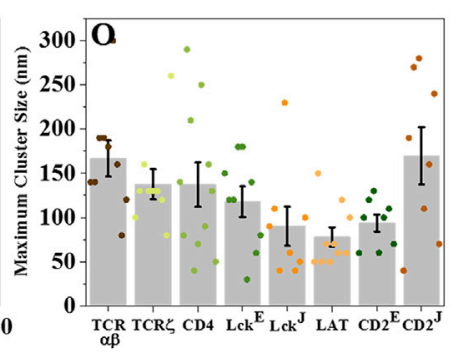

(legend on next page) 
Jurkat T cells (Figures 2B and 2E). Indeed, $96.0 \% \pm 1.2 \%$ of the molecules were localized to microvilli (Figure $2 \mathrm{M}$; Table S1), and the $\delta$ Count/ $\delta$ Area plot was very steep (Figure $2 \mathrm{~N}$ ). The maximum cluster size of TCR $\zeta$ receptors was $138 \pm 17 \mathrm{~nm}$ (Figure 2O), again matching the microvillar diameter.

CD4

This TCR co-receptor is a glycoprotein universally found on the surface of helper T cells and subsets of dendritic cells (Jardine et al., 2013; Roh et al., 2015; Taniuchi, 2018). It assists the TCR complex in forming connection to the APC by binding MHC class II molecules, and it also recruits the key Src kinase Lck to the TCR. Importantly, Jurkat T cells display only CD4 and not CD8 on their surface (Roose et al., 2003). We found that $94.4 \% \pm 1.1 \%$ of the CD4 molecules are localized to the microvilli of Jurkat T cells (Figures 2C and 2F; see also Figures $2 \mathrm{M}$ and S2; Table S1). The slope of the $\delta$ Count $/ \delta$ Area plot (Figure $2 \mathrm{~N}$ ) was the largest among all the proteins measured. The maximum cluster size calculated for CD4 was $137 \pm 25 \mathrm{~nm}$ (Figure 20).

Lck

Following engagement of the TCR by an antigen on the APC, Lck phosphorylates the intracellular domains of CD3 and TCR $\zeta$ and later on Lck and TCR co-localize in the center of the IS (Rossy et al., 2012). Lck was also found in CD2 clusters of activated T cells (Rossy et al., 2012). We observed that in both human effector T cells (Figure 2G) and Jurkat cells (Figure 2H), Lck molecules localize to a large extent to microvilli (for localization maps at the $-400 \mathrm{~nm}$ plane, see Figures S2A and S2B). $74.5 \% \pm 3.5 \%$ of all Lck molecules were localized on the microvillar regions of human effector T cells based on the $0 \mathrm{~nm}$ plane images, whereas $65.4 \% \pm$ $4.7 \%$ of the molecules were localized on the microvillar regions based on the $-400 \mathrm{~nm}$ plane images (Figures $2 \mathrm{M}$ and S2G). A similar picture arose in the case of Jurkat cells, with $76.3 \% \pm$ $4.1 \%$ of all Lck molecules localized on microvilli regions based on $0 \mathrm{~nm}$ plane images, and $59.6 \% \pm 4.8 \%$ of the molecules localized on microvilli regions based on the $-400 \mathrm{~nm}$ plane images (Figures $2 \mathrm{M}$ and $\mathrm{S} 2 \mathrm{G}$ ). These fractions are, however, significantly smaller than those of TCR $\alpha \beta, \mathrm{TCR} \zeta$, and CD4. Thus, although Lck molecules interact with CD4 molecules (Foti et al., 2002), it seems that not all of them are directly linked to these co-receptor molecules, as also suggested by another study (Stephen et al., 2012).

LAT

This adaptor protein is phosphorylated by ZAP-70 following activation of TCRs and initiates a cascade of events involving multiple signaling molecules, which leads to the formation of the IS (AIcover et al., 2018). Like Lck, LAT resides in intracellular vesicles exchanging with the plasma membrane (Alcover et al., 2018). We found that although LAT molecules were distributed throughout the Jurkat T cell membrane, they still showed a significant preference for microvilli (Figures $2 \mathrm{I}$ and 2M; for the localization map and analysis of LAT at the $-400 \mathrm{~nm}$ plane, see Figures $\mathrm{S} 2 \mathrm{C}, \mathrm{S} 2 \mathrm{G}$, and $\mathrm{S} 2 \mathrm{H}$ ). The fraction of LAT molecules localized on microvilli at the $0 \mathrm{~nm}$ and $-400 \mathrm{~nm}$ plane images was $67.8 \%$ $\pm 2.9 \%$ and $54.6 \% \pm 2.3 \%$, respectively (Figures $2 \mathrm{M}$ and $\mathrm{S} 2 \mathrm{G}$ ). The initial slope of the $\delta$ Count/ $\delta$ Area plot (Figure $2 \mathrm{~N}$ ) was not as high as for other membrane proteins but still significantly larger than that of CD45 (Table S2). Interestingly, LAT clusters tended to be smaller than those of TCR components (maximum size, $78 \pm 10 \mathrm{~nm}$; Figure 2O), but their size agreed well with previous studies (Lillemeier et al., 2010; Williamson et al., 2011).

\section{CD2}

CD2 is an adhesion molecule that binds LFA-3 (CD58) on the APC membrane and recruits essential kinases such as phosphoinositide 3-kinase to the vicinity of the TCR signaling complexes during the initial stages of the immune response, thereby amplifying TCR signaling (Kaizuka et al., 2009; Makgoba et al., 1989; Wilkins et al., 2003). We found that CD2 molecules are also highly enriched on microvilli of human effector T cells (Figures $2 \mathrm{~J}$ and $\mathrm{S} 2 \mathrm{D}$ ) and Jurkat cells (Figures $2 \mathrm{~K}$ and $\mathrm{S} 2 \mathrm{E}$ ), with more than $90 \%$ of the molecules residing on these projections (Figure 2M; for a localization map at the $-400 \mathrm{~nm}$ plane, see Figure S2G). The $\delta$ Count $/ \delta$ Area plot is flat for in the first $\sim 50 \mathrm{~nm}$ but then decays (Figure $2 \mathrm{~N}$ ), also pointing to the essentially exclusive residence of these molecules on microvilli. The maximal cluster size of CD2 molecules on the microvilli of effector and Jurkat cells was $94 \pm 10$ and $170 \pm 32 \mathrm{~nm}$, respectively (Figure 20). Thus, following TCR occupancy by ligand, LFA-3 occupancy of CD2 molecules may take place in the vicinity of the TCR and instantaneously amplify the TCR signal.

\section{CD45}

CD45 is an abundant protein tyrosine phosphatase. This transmembrane protein has been shown to operate as a modulator of the sensitivity of $\mathrm{T}$ cells to activation by associating with several membrane proteins, including the TCR complex, CD4/ CD8, Lck, and ZAP-70 (Alcover et al., 2018; Davis and van der Merwe, 2006). In accordance with our previous finding in human peripheral T lymphocytes (Jung et al., 2016), we found that CD45 also distributed throughout the membrane of Jurkat $T$ cells

Figure 2. Mapping the Distribution of Membrane Proteins Involved in T cell Signaling in Relation to Microvill

(A-F) T cell receptor (TCR)-related proteins are localized to the microvilli. Positions of protein molecules obtained from SLN (white dots) are superimposed on membrane topography maps of Jurkat T cells obtained from VA-TIRFM. The labels " $0 \mathrm{~nm}$ " and "- $400 \mathrm{~nm}$ " in panel titles refer to the two focal planes sampled in the super-resolution experiments. Scale bars, $1 \mu \mathrm{m}$

(G-L) Localization maps of additional membrane proteins involved in initial T cell activation. Positions of protein molecules obtained from SLN (white dots, black dots in I and L) at the $0 \mathrm{~nm}$ plane on either Jurkat T cells or human effector T cells are superimposed on membrane topography maps obtained from VA-TIRFM. The color bars represent distance from the glass in nanometers $(\mathrm{nm})$. Scale bars, $1 \mu \mathrm{m}$. (M-O) Quantitative measures for the distribution of proteins on the T cell surface.

(M) Percentage of molecules on microvillar (MV) regions of the membrane. The values for individual cells are shown as dots in the plot.

(N) Cumulative increase of the fraction of total molecules on each cell as a function of the distance from the central microvilli region, normalized by the cumulative increase in the fraction of area ( $\delta$ Count/ $\delta$ Area) as a function of distance from microvilli.

(O) Maximum cluster sizes. The values for individual cells are shown as dots in the plot. The gray bars are averages over all cells measured at the $0 \mathrm{~nm}$ plane. Error bars represent standard errors of the mean (SEM). The E and J superscripts following some protein names denote values obtained with effector cells and Jurkat cells, respectively. When no superscript is shown, the values were obtained with Jurkat cells. 

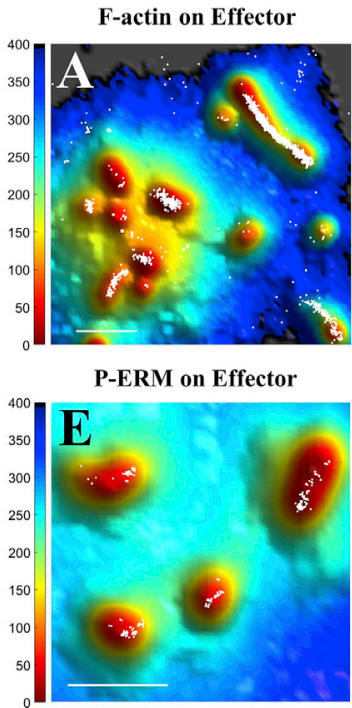
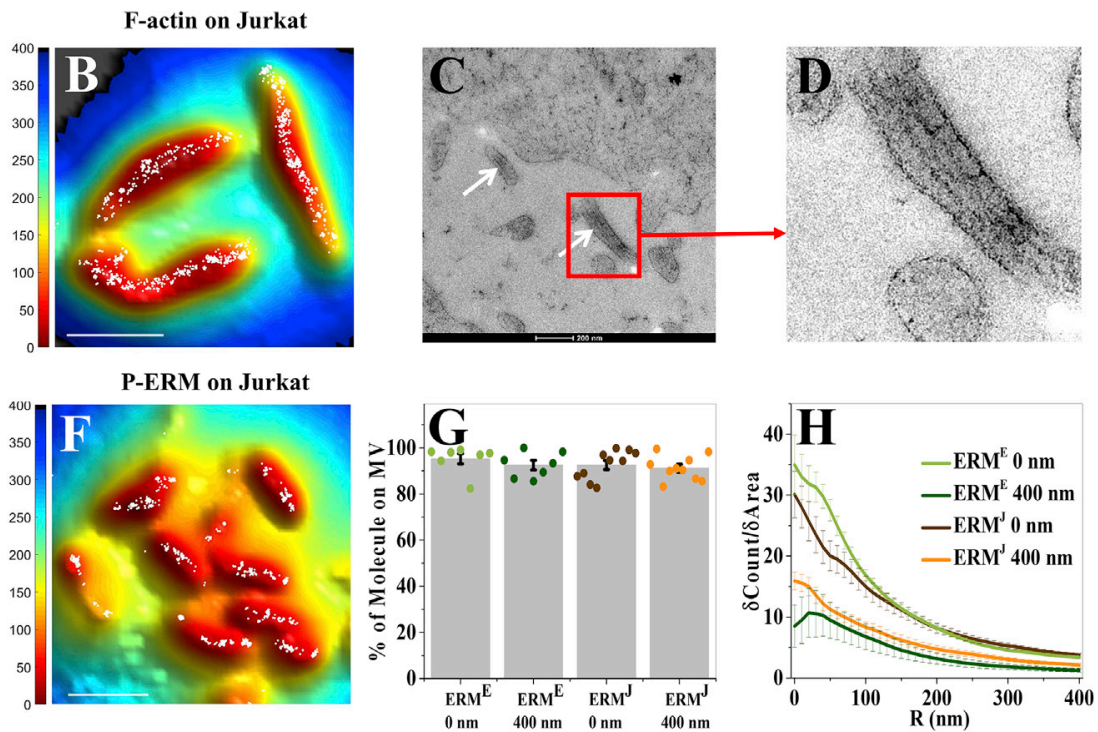

Figure 3. F-Actin and p-ERM Both Localize within the Microvilli of T Cells

(A and B) Super-resolution localization maps of Alexa-Fluor-647-phalloidin-labeled F-actin (white dots) overlaid with the 3D surface reconstruction map, showing that F-actin localizes within microvilli. The color bars represent distance from the glass in $\mathrm{nm}$. Scale bars, $1 \mu \mathrm{m}$.

(C) TEM images of Jurkat cells showing the parallel actin filaments within microvilli (white arrows).

(D) The zoomed image of the section indicated by red box in (C).

( $E$ and F) Super-resolution localization maps of $p$-ERM molecules (white dots) overlaid with the 3D surface reconstruction map. The color bars represent distance from the glass in $\mathrm{nm}$. Scale bar, $1 \mu \mathrm{m}$.

(G) Percentage of $p$-ERM molecules on microvillar (MV) regions at the $0 \mathrm{~nm}$ and $-400 \mathrm{~nm}$ planes for effector cells $\left(\mathrm{ERM}^{\mathrm{E}}\right)$ and Jurkat cells $\left(\mathrm{ERM}^{\mathrm{J}}\right)$. The values for individual cells are shown as points in the plot. Error bars represent SEM.

$(\mathrm{H})$ Cumulative increase of the fraction of total molecules on each cell as a function of the distance from the central microvilli region, normalized by the cumulative increase in the fraction of area as a function of distance from microvilli ( $\delta$ Count/ $\delta$ Area). The plots are averages over all cells measured. Error bars represent $S E M$.

(Figure 2L; for localization at the $-400 \mathrm{~nm}$ plane, see Figure S2F). Only $31.6 \% \pm 2.0 \%$ of CD45 molecules localized in microvilli regions (Figure $2 \mathrm{M}$ ). The near-zero slope of the $\delta$ Count/ $\delta$ Area plot for CD45 (Figure 2N) also pointed to a homogeneous distribution of the CD45 molecules all over the membrane. Interestingly, two recent studies also demonstrated a uniform distribution of CD45 on the T cell membrane (Cai et al., 2017; Fernandes et al., 2019).

\section{TCR Assemblies on Microvilli Colocalize with Activated ERMs and F-Actin}

The role of the actin cytoskeleton in receptor clustering and IS formation has been extensively studied (Burkhardt et al., 2008; Fritzsche et al., 2017; Grakoui et al., 1999; Lillemeier et al., 2006; Ritter et al., 2017; Roybal et al., 2015; Tamzalit et al., 2019). In our own previous work, we found that the localization of TCR $\alpha \beta$ molecules on microvilli is disturbed upon disruption of the actin cytoskeleton with latrunculin A (Jung et al., 2016). We decided to shed further light on the relationship between the actin cytoskeleton and selective localization of $\mathrm{TCR} \alpha \beta$ molecules.

We first tested the effect of activation-induced T cell spreading on ICAM-1 on the topographical distribution of TCR $\alpha \beta$ molecules. TCR stimulation induces strong actin cytoskeleton remodeling and increased adhesion via LFA-1 integrin and its ligand, ICAM-1, leading to stable T cell spreading (Bunnell et al., 2001; Grakoui et al., 1999; Stewart et al., 1996). Spreading may influ- ence the structure of microvilli, as shown in chemokine-activated T cells (Brown et al., 2003), and may consequently affect the TCR distribution. To probe the effect of spreading, we stimulated Jurkat $\mathrm{T}$ cell with anti-CD3 antibodies at $37^{\circ} \mathrm{C}$ and at the same time let them interact with an ICAM-1-coated surface for $3 \mathrm{~min}$. We fixed the cells, labeled the membrane with FM143fx, and imaged the TCR distribution as described above. CD3-stimulated Jurkat cells readily spread over the ICAM- 1 surface (Figure S3A), and the typical microvilli structure of these cells prior to stimulation was almost entirely lost, with essentially all TCR $\alpha \beta$ molecules evenly distributed throughout the membrane (Figures S3B and $\mathrm{S} 3 \mathrm{C})$.

To observe actin organization inside the microvilli of T cells, we labeled the membrane of human effector $\mathrm{T}$ cells and Jurkat $\mathrm{T}$ cells with FM143FX and filamentous actin (F-actin) with Alexa-Fluor-647-conjugated phalloidin (a selective marker of F-actin; Figure 3). Using the combination of VA-TIRFM and SLN, we found that actin filaments fill the space within the microvilli in both human T-effector cells and Jurkat cells (Figures $3 \mathrm{~A}$ and $3 \mathrm{~B}$ ). To further confirm these findings, we performed transmission electron microscopy (TEM) on thin sections of resinembedded Jurkat cells. We observed parallel actin filaments within microvilli (Figures $3 \mathrm{C}$ and $3 \mathrm{D}$ ), similar to the observation of Majstoravich et al. (2004) with lymphoma cells. Interestingly, these images do not show actin within the cytoplasm of the cells, which is due to the limited penetration depth of TIRF-based microscopy, as has been noted before (Babich et al., 2012; Bunnell 

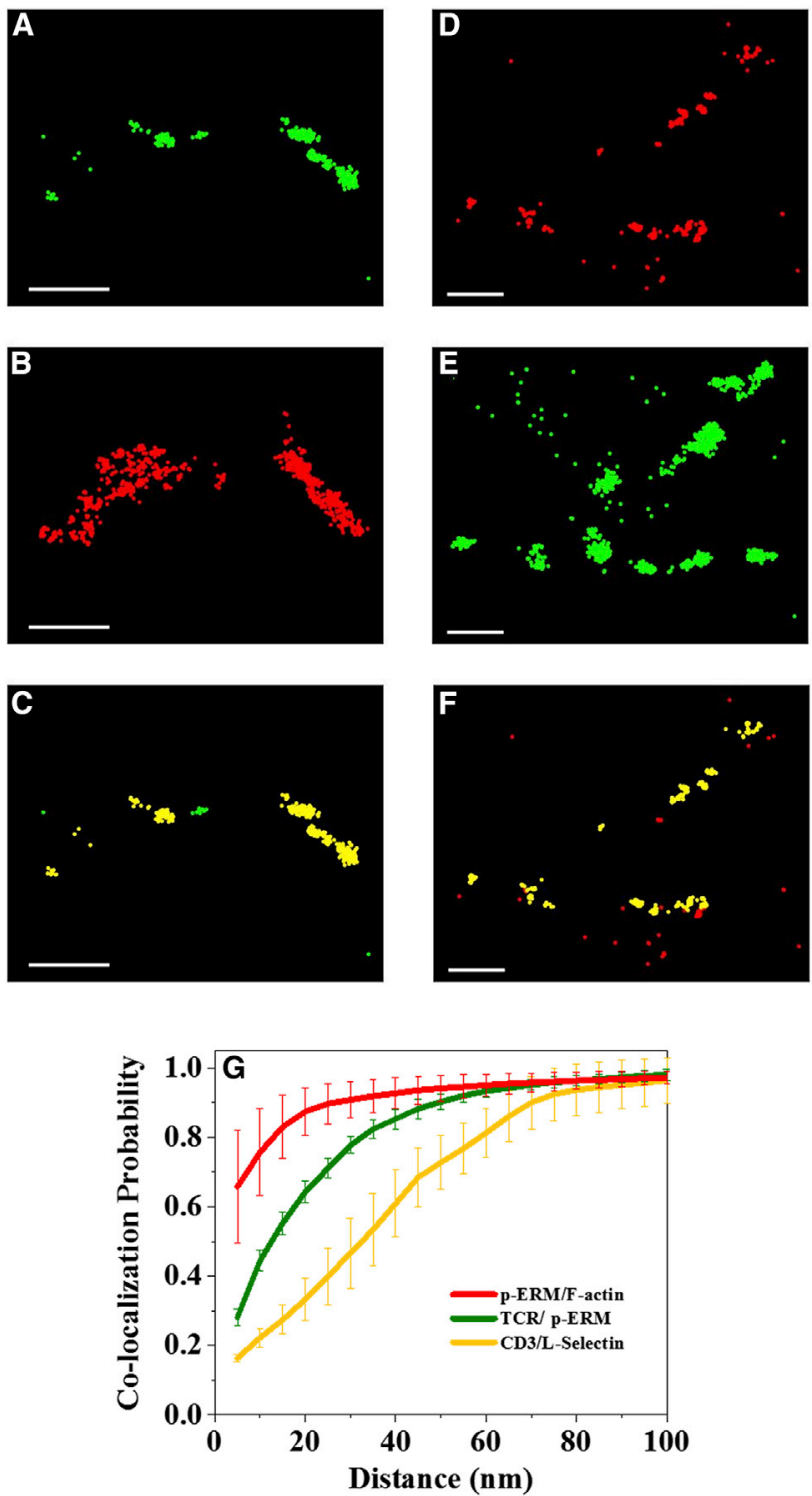

Figure 4. The CP Reveals Strong Co-localization of p-ERM with F-Actin and TCR $\alpha \beta$

(A) Super-resolution image of a Jurkat cell labeled with Alexa-Fluor-568-conjugated anti-phospho-ERM antibodies (green).

(B) Super-resolution image of the same cell labeled with Alexa Fluor 647 phalloidin (red), which stains F-actin.

(C) Same as (A), but p-ERM molecules that have at least one actin molecule within a radius of $30 \mathrm{~nm}$ are marked yellow. The number of these molecules, divided by the total number of $p$-ERM molecules, is the co-localization probability (CP) for this pair at $30 \mathrm{~nm}$.

(D) Super-resolution image of a Jurkat cell labeled with Alexa Fluor 647 antihuman TCR $\alpha \beta$ antibodies (red).

(E) Super-resolution image of the same cell labeled with Alexa-Fluor-568conjugated anti-phospho-ERM antibodies (green).

(F) Same as in (D), but TCR $\alpha \beta$ molecules that have at least one p-ERM molecule within a radius of $30 \mathrm{~nm}$ are marked yellow. The number of these molecules, divided by the total number of TCR $\alpha \beta$ molecules, is the CP for this pair at $30 \mathrm{~nm}$. Scale bars, $0.5 \mu \mathrm{m}$.

(G) $\mathrm{CP}$ as a function of distance for the pairs of molecules indicated in the legend. Error bar represents SEM. At least five cells are measured for each pairs of proteins. et al., 2001, 2002; Fritzsche et al., 2017; Smoligovets et al., 2012). In contrast, we found that a 3D SLN setup can image the actin meshwork deep inside resting Jurkat cells (Figures S3D and S3E).

ERM (ezrin, radixin, and moesin) proteins are well known for linking the actin cytoskeleton cortex with plasma membrane proteins (Fehon et al., 2010; McClatchey, 2014). They also play a crucial role in microvilli formation (Brown et al., 2003; Tsukita and Yonemura, 1999). In T cells, only ezrin and moesin are expressed (Shaffer et al., 2009). The $\mathrm{N}$-terminal domains (so-called FERM domains; Bretscher et al., 2002) of ERM proteins interact with membrane proteins, while their $\mathrm{C}$-terminal domains bind cortical actin (Bretscher et al., 2002). Notably, this membranecytoskeleton linkage occurs mainly when the ERM C-terminal domain is phosphorylated (Gautreau et al., 2000). It has also been shown that after antigen sensing by the TCR, the phosphorylated ERM proteins (referred to as $\mathrm{p}$-ERM proteins) are dephosphorylated and rapidly de-anchor the actin cytoskeleton cortex from the plasma membrane (Faure et al., 2004). It was further reported that ERM proteins also control the pre-organization of $B$ cell receptor (BCR) microclusters on the plasma membrane of resting B cells (Treanor et al., 2011). Using TEM, Bretscher and coworkers showed early on that ezrin is localized in the apical microvilli of epithelial cells (Berryman et al., 1993). These accumulated findings directed us to investigate the involvement of $p$-ERM proteins in the anchoring of TCR proteins to microvilli.

We first examined whether p-ERM proteins are localized within microvilli. We labeled p-ERM molecules with AlexaFluor-647-conjugated antibodies and the membrane with FM143FX dye. Combined VA-TIRFM and SLN imaging demonstrated that $\mathrm{p}$-ERM proteins were segregated within microvilli of both human T-effector cells and Jurkat cells (Figures $3 \mathrm{E}$ and 3F). More than $90 \%$ of $p$-ERM proteins were found to be segregated to the microvillar regions in both imaging planes (Figure $3 \mathrm{G}$ ), and the steepness of $\delta$ Count/ $/$ Area plot (Figure $3 \mathrm{H}$ ) was very high, supporting the confinement of these molecules within microvilli.

We further reasoned that if the $\mathrm{p}$-ERM proteins act as a bridge to connect TCR $\alpha \beta$ to the cortical actin cytoskeleton, then these three molecules should co-localize. We therefore performed two-color super-resolution microscopic experiments to find the degree of co-localization of these molecules in pairs on Jurkat $\mathrm{T}$ cells with nanometer resolution. We developed an analysis scheme to obtain the fraction of molecules that are co-localized on microvilli. To this end, we introduced the distance-dependent co-localization probability (CP), which is the probability that a molecule of one type will have at least one partner of the other type within a specified interaction distance. The CP for molecules $i$ and $j$ within distance $R$ is given by $N_{i j}(R) / N_{i}$, where $N_{i}$ is the total number of detected points of molecule $i$ and $N_{i j}(R)$ is the number of points of molecule $i$ that have at least one point of molecule $j$ within $R$.

The CP calculation is demonstrated for $p$-ERM and F-actin in Figures 4A-4C. SLN images are shown in Figures $4 A$ and $4 B$, and Figure $4 \mathrm{C}$ shows in yellow molecules of $p$-ERM that have at least one F-actin molecule within one selected distance $(30 \mathrm{~nm})$. Similarly, Figures 4D and 4E demonstrate the CP calculation for 
molecules of TCR $\alpha \beta$ and $p-E R M$. The CP functions calculated for these two pairs over the whole range of interaction distances from 0 to $100 \mathrm{~nm}$ are presented in Figure 4G (p-ERM/F-actin in red and TCR/p-ERM in olive). The two CP functions rise to high values over a short range of $R$ values. To obtain a negative control we repeated the calculation of CP based on images of L-selectin and CD-3, two proteins enriched within microvilli but not known to directly interact with each other (Figure 4G, orange, and Figures S3F-S3I). For a quantitative comparison of the this $\mathrm{CP}$ function to the two previous ones, we performed Kolmogorov-Smirnov tests separately for each $R$. Based on these tests, we concluded that over the distance range 0-60 $\mathrm{nm}$ the difference between the CP values of F-actin/p-ERM or p-ERM/ TCR on one hand and L-selectin/CD3 on the other hand is statistically significant.

To further support the CP analysis, we also applied the colocalization method recently introduced by Huang and coworkers (Schnitzbauer et al., 2018), and the results are described in Figure S3I. Taken together, the two co-localization experiments indicated that the TCR $\alpha \beta$ heterodimer, p-ERM, and $\mathrm{F}$-actin are interacting with each other, suggesting a key role for $p$-ERM in connecting the TCR $\alpha \beta$ complex to the actin cytoskeleton of $\mathrm{T}$ cell microvilli.

\section{Modulating the Microvillar Distribution of TCR $\alpha \beta$ by} Overexpression of a Dominant-Negative Ezrin Fragment To test the direct role of $\mathrm{p}$-ERM proteins in regulating the formation of the microvilli of T cells and maintaining TCR $\alpha \beta$ on these microvilli, we transfected $T$ cells with a dominant-negative construct of ezrin. Such constructs have been used as a tool to study the function of ERM proteins in various physiological processes, including TCR-mediated T cell activation (Bretscher et al., 2002; Brown et al., 2003; Faure et al., 2004; Roumier et al., 2001). In particular, constructs containing only the N-terminal FERM domain of ezrin and lacking the C-terminal actin-binding domain were shown to block F-actin association with multiple members of the ERM family (Allenspach et al., 2001; Bretscher et al., 2002; Brown et al., 2003; Delon et al., 2001; Faure et al., 2004; Malissen and Bongrand, 2015). We transfected Jurkat cells with cDNA encoding a vesicular stomatitis virus (VSV)-tagged construct (Roumier et al., 2001) containing the FERM domain of ezrin (which we termed $\mathrm{N}$-ter ezrin) and also with the cDNA encoding a VSV-tagged construct containing only the C-terminal end of ezrin (C-ter ezrin). N-ter ezrin will only bind with membrane proteins, but not with F-actin. It has been reported that $\mathrm{N}$-ter ezrin also causes dephosphorylation of endogenous p-ERM (Faure et al., 2004). Thus, N-ter ezrin serves as a dominant-negative version of the ERM proteins. In contrast, C-ter ezrin cannot bind with membrane proteins as it lacks the FERM domain. It has been shown that the C-ter construct induces low-to-no perturbation of ERM functions (Algrain et al., 1993; Speck et al., 2003). Therefore, it has been mostly used as a negative control. It is likely that this fragment cannot compete with the endogenous protein in binding to the cytoskeleton, which prevents it from interfering with the function of the native ERM proteins.

To follow the distribution of TCR $\alpha \beta$ distribution on the surface of $\mathrm{N}$-ter ezrin and $\mathrm{C}$-ter ezrin transfected Jurkat cells, we labeled the membrane with FM143FX, TCR $\alpha \beta$ with Alexa-Fluor-647tagged antibodies, and the VSV tag of $\mathrm{N}$-ter ezrin or $\mathrm{C}$-ter ezrin with Alexa-Fluor-405-conjugated anti-VSV-G epitope tag antibody. Based on the intensity of Alexa Fluor 405, we were able to characterize cells as transfected at a high, medium, or low level (Figures S4A-S4H). Deformation of membrane structure and destruction of microvillar structure correlated with transfection level (Figures S4I-S4M). This finding agrees well with Brown et al. (2003), who used SEM imaging to show that high N-ter ezrin transfection abolishes microvilli on the surface of Jurkat cells. In contrast, the effects of C-ter ezrin transfection on microvilli number and length were negligible (Figures S4J).

While C-ter ezrin did not affect the localization of TCR $\alpha \beta$ to microvilli even at high transfection levels, the distribution of $\mathrm{TCR} \alpha \beta$ was modified upon increasing $\mathrm{N}$-ter ezrin transfection levels (Figures S4N-S4U). The percentage of TCR $\alpha \beta$ molecules on the microvilli of C-ter ezrin transfected Jurkat cells was found to be $92.0 \% \pm 1.9 \%$, which is similar to that of non-transfected cells (Figure $5 A$ ), and the $\delta$ Count/ $\delta$ Area plot for these cells was as steep as that of non-transfected Jurkat cells (Figure $5 B$ ). On the other hand, the percentage of TCR $\alpha \beta$ molecules on the microvilli of $\mathrm{N}$-ter ezrin transfected Jurkat cells decreased from $81.0 \%$ $\pm 2.2 \%$ for cells with low transfection levels to $59.2 \% \pm 3.8 \%$ for cells with medium transfection levels and down to $31.5 \% \pm 3.6 \%$ for cells with high transfection levels (Figure 5A). The slopes of $\delta$ Count/ $\delta$ Area plots also decreased in a similar fashion (Figure $5 \mathrm{~B}$ ). Furthermore, the maximum cluster size of TCR $\alpha \beta$ molecules, as obtained from the Ripley's $\mathrm{K}$ function analysis decreased upon increasing $\mathrm{N}$-ter ezrin transfection efficiency (Figure 5C). Importantly, the degree of localization of TCR $\alpha \beta$ on microvilli was found to be inversely correlated with the level of $\mathrm{N}$-ter ezrin transfection (Figure 5D). Although it was found that the number of microvilli decreases with dominant-negative ERM, this should not automatically mean that the TCRs disperse; they might in principle cluster on the remaining microvilli. The observation that TCR clusters disappear together with microvilli (with those on the remaining microvilli becoming smaller) and that TCR molecules disperse on the cell body is therefore a novel finding, which supports the important conclusion that TCR cluster formation and microvilli stability are related processes key for optimal signal transduction. This connection makes sense, since ERMs are multifunctional proteins that guarantee interactions between cortical actin cytoskeleton and plasma membrane components. They help to compartmentalize receptors at the plasma membrane and are responsible for microvilli formation and/or stability (Arpin et al., 2011; Gautreau et al., 2000; Treanor et al., 2011). Thus, the negative correlation between the degree of localization of TCR $\alpha \beta$ on microvilli and the level of N-ter ezrin transfection confirms our hypothesis that $\mathrm{p}$-ERM proteins maintain the $\mathrm{TCR} \alpha \beta$ complex on the microvilli of T cells to ensure optimal recognition of antigen and initial TCR signaling.

We then addressed the functional consequences of altered distribution of TCRs in relation to microvilli. To this end, Jurkat cells transfected with $\mathrm{N}$-ter ezrin were stimulated by incubating them with Raji cells loaded with the superantigen staphylococcal enterotoxin E (SEE) or Raji cells alone as a control (Lasserre et al., 2010). We then quantified ERK1/ERK2 kinase activation as a measure of TCR-induced signaling by monitoring 
A
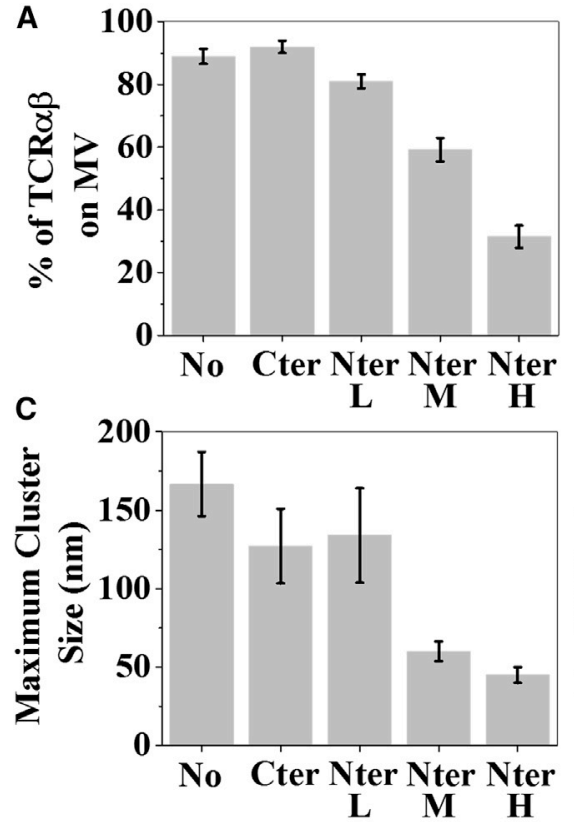
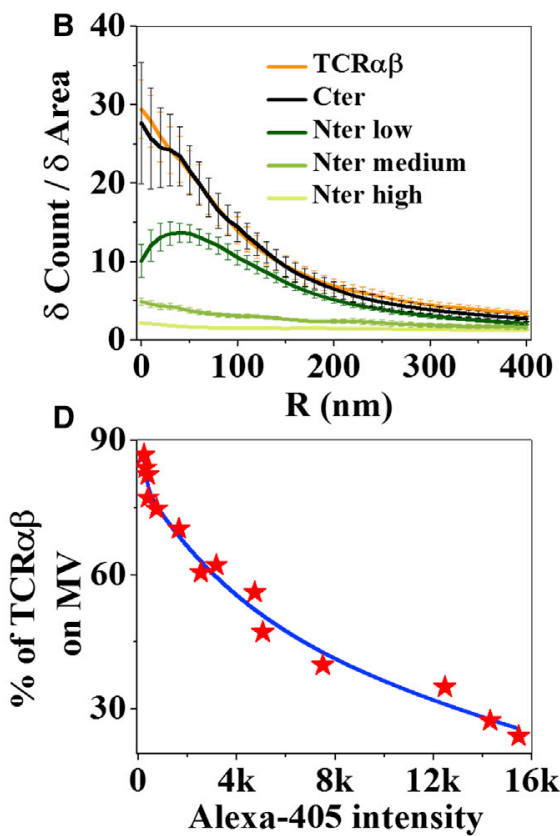

Figure 5. Effect of Dominant-Negative ( $N$ ter) and Negative Control (C-ter) Ezrin Transfection on the Localization of TCR $\alpha \beta$ with respect to 3D Topography of Jurkat $T$ Cells

(A) Percentage of TCR $\alpha \beta$ molecules on microvilli as a function of different transfection levels. No, no transfection; L, low transfection; $\mathrm{M}$, medium transfection; and $\mathrm{H}$, high transfection. Error bars represent SEM.

(B) Cumulative increase of the fraction of total molecules on each cell as a function of the distance from the central microvilli region, normalized by the cumulative increase in the fraction of area

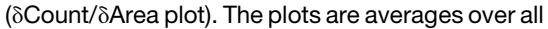
cells measured. Error bars represent SEM. 9, 10, and 14 cells are measured respectively for no, $\mathrm{C}$-ter, and $\mathrm{N}$-ter ezrin transfection.

(C) Change of maximum cluster sizes of $\mathrm{TCR} \alpha \beta$ molecules in response to different transfection levels (labels as in A). Error bars represent SEM. (D) Correlation of percentage of TCR $\alpha \beta$ molecules in the microvilli regions and the transfection efficiency, as measured through Alexa Fluor 405 intensity. The blue line is a guide to the eye. phosphorylation levels using flow cytometry with intracellular staining. As shown in Figure 6A (left panel), we gated on cells expressing either high or low levels of the N-ter ezrin construct (N-ter-ezrin-negative cells were not included in the analysis, since they contain a mixture of both Jurkat and Raji cells). Interestingly, the percentage of phospho-ERK (pERK)-positive cells was significantly higher in cells with low $\mathrm{N}$-ter ezrin expression than in those with high $\mathrm{N}$-ter ezrin expression (Figure 6A, right panel). Based on three independent experiments, the average percentage of pERK-positive cells was $22.7 \% \pm 2 \%$ in cells with low $\mathrm{N}$-ter-ezrin expression and only $12.6 \% \pm 2.5 \%$ in cells with high $\mathrm{N}$-ter ezrin expression (Figure 6B). This difference was found to be significant $(p<0.001)$. Our results indicate that higher expression of N-ter ezrin, leading to TCR displacement from microvilli, results in impaired T cell activation.

\section{DISCUSSION}

The $T$ cell surface is covered by numerous elastic actin-rich finger-like protrusions known as microvilli. Although $\mathrm{T}$ cell microvilli have been classically implicated in lymphocyte adhesion to blood vessels (von Andrian et al., 1995), the role of these membrane structures in T cell recognition of APCs inside various tissues is poorly understood. Multiple models that attempt to relate $T$ cell function with the organization of receptors on the cell surface treat the plasma membrane as a $2 \mathrm{D}$ sheet rather than a 3D surface (Davis and van der Merwe, 2006; Lillemeier et al., 2006, 2010; Roh et al., 2015; Sezgin et al., 2017; Sherman et al., 2011; Simons and Sampaio, 2011). Recent studies have begun to unearth the pivotal role of microvilli as sensors involved in the initial stages of the TCR response (Cai et al., 2017; Jung et al., 2016; Kim et al., 2018; Razvag et al., 2018). In this work, we investigated the properties of microvilli that make them effective sensors.
To that end, we probed the localization of multiple T cell membrane proteins with respect to microvilli. We mapped the positions of seven key membrane molecules known to be involved in the initial stages of $T$ cell activation with respect to the $3 D$ topography of the T cell membrane, both in human effector cells and Jurkat T cells. We found that many (most?) of these proteins reside almost exclusively on microvilli. Among these are components of the TCR complex, including TCR $\alpha \beta$ and TCR $\zeta$. (Another component of the TCR complex, CD3e, was demonstrated to reside on microvilli in our previous work; Jung et al., 2016.) Importantly, CD4, the co-receptor that engages the MHC class II-peptide complex and improves TCR sensitivity by increasing its proximity to its proximal tyrosine kinase Lck (Foti et al., 2002), is also co-localized with its TCR partner on microvilli. Furthermore, the co-stimulatory adhesion molecule CD2 was also found to be segregated on microvilli. This indicates that in addition to the TCR and its co-receptor complex, critical costimulatory receptors are also enriched on microvilli, probably in proximity with the TCR complexes, thus amplifying the TCR signals delivered during the initial stages of $T$ cell activation. Like CD2, CD28 also functions as a co-stimulatory receptor that amplifies TCR signals in naive T cells (Esensten et al., 2016). It would be therefore interesting to investigate in future work whether CD28 is also enriched on microvilli and whether CD2 and CD28 co-localize on these cellular projections. Two proteins critically involved in the initial TCR signaling steps, namely Lck and LAT, were also found to be enriched on microvilli, with $\sim 76 \%$ and $\sim 68 \%$ of these molecules, respectively, located on these $\mathrm{T}$ cell projections. Thus, there is a pool of all the major TCR signaling molecules that reside together on T cell microvilli in order to facilitate the initial stages of TCR triggering following APC encounter. The intermediate levels of enrichment of some molecules on microvilli are consistent with the possibility that additional pools of TCR $\zeta$, Lck and LAT 


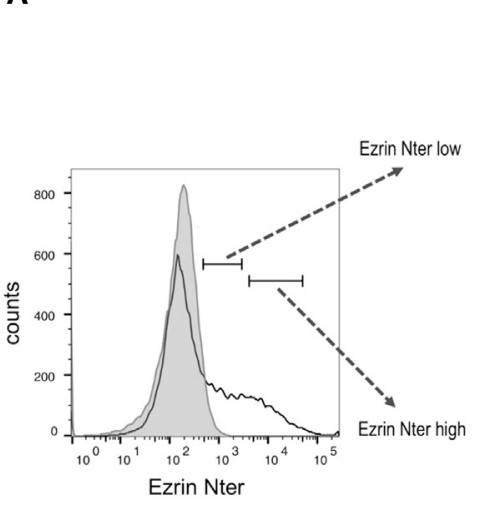

B
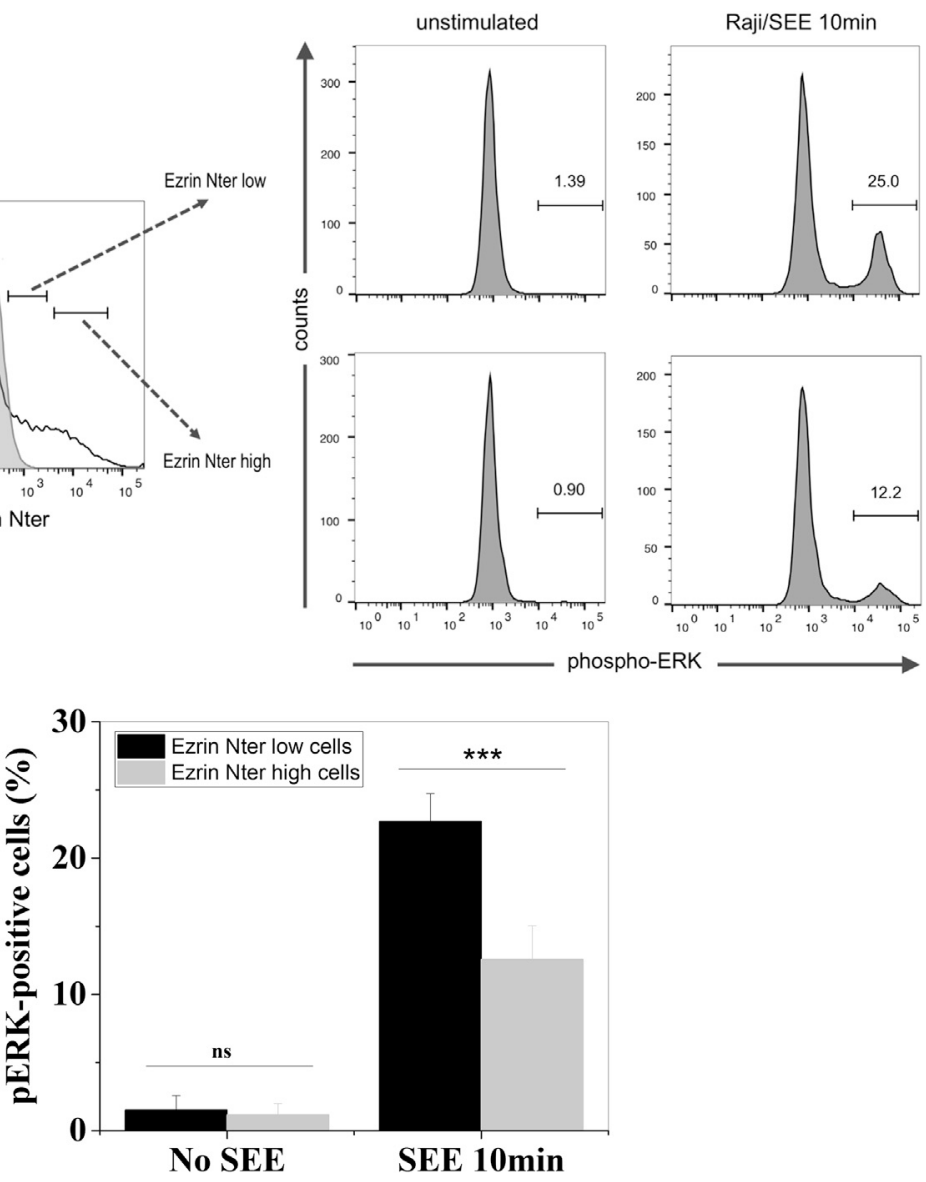

molecules associated with endosomal vesicular compartments are later recruited to the vicinity of the initial TCR-pMHC complexes, possibly to amplify the initial TCR signaling (Soares et al., 2013). It remains unknown, however, why a significant fraction of Lck and LAT molecules are found on cell body regions rather than on microvilli. Interestingly, a pool of Lck molecules that are not associated with CD4 was reported by Stephen et al. (2012). It is therefore possible that this Lck pool resides on the cell body of $\mathrm{T}$ cells and operates on a different subset of substrates. Moreover, some Lck and LAT molecules were found in endosomal vesicles, whose position with respect to the plasma membrane may vary (Bouchet et al., 2017; Soares et al., 2013).

A recent report (Rossboth et al., 2018) suggested that observations of TCR clusters on the T cell membrane (Hu et al., 2016; Lillemeier et al., 2006, 2010; Pageon et al., 2016; Roh et al., 2015; Sherman et al., 2011) were due to imaging artifacts and that all TCR machineries are randomly distributed on the surface of T cells. However, in that paper, TCR-stimulated T cells were spread on ICAM-1-coated surfaces. Our own experiments with ICAM-1-coated surfaces conclusively indicate that the observation of random distribution of TCRs on the plasma membrane of T cells is likely the outcome of both the TCR stimulation and the spreading process on ICAM-1. In contrast to the T cells studied on ICAM-1, which model APC-bound T cells, our studies
Figure 6. ERK Activation Assay to Address the Functional Consequences of Altered Distribution of TCRs in Relation to Microvilli Jurkat cells transfected with $\mathrm{N}$-ter ezrin expression plasmid or empty vector were incubated with Raji cells, alone or pre-loaded with SEE. After fixation, cells were permeabilized and stained with antiVSV-G tag (to assess $\mathrm{N}$-ter ezrin expression) and anti-phospho-ERK antibodies.

(A) Left: transfected Jurkat cells were gated based on the expression of low or high amounts of $\mathrm{N}$-ter ezrin (left panel, black line). Gray-filled histogram shows labeling of control cells transfected with empty vector. Right: phospho-ERK staining of low (top row) or high (bottom row) N-ter-ezrin-expressing cells, either unstimulated (Raji) or stimulated with SEE-loaded Raji (Raji+SEE). Numbers over the horizontal bars indicate the percentage of phospho-ERK-positive cells in each sample. The figure shows a representative experiment out of three performed.

(B) Quantification of phospho-ERK-positive cells in low and high $\mathrm{N}$-ter-ezrin-expressing cells. Histogram shows the average \pm SEM from three independent experiments. Statistical analysis was performed with a one-way ANOVA (ns, no significant difference; ${ }^{\star \star \star} p<0.001$ ).

of the distribution of various surface molecules on microvilli involved resting $T$ cells fixed prior to APC encounter. These $T$ cells retained their preformed morphology as well as the preformed segregation of their TCR machineries and proximal signaling molecules on their microvilli. It should be noted that the clustering of $T$ cell proteins we observed here has a clear mechanistic origin (i.e., segregation on microvilli). Thus, our results link for the first time the preorganization of TCR assemblies on resting T cells to the presence of microvilli, which are constantly scanning for antigenic signals on various APCs (Cai et al., 2017).

To shed light on the mechanism of selective anchoring of TCRassociated molecules on microvilli, we studied the distribution of TCR $\alpha \beta$ receptors with respect to actin filaments and their phosphorylated ERM linkers. We introduced the CP analysis, which allowed us to point to a statistically significant interaction between these three components. This finding, together with the negative effect of $\mathrm{N}$-ter ezrin on TCR $\alpha \beta$-actin assemblies, suggests that the actin cytoskeleton is intimately involved in the organization of TCR assemblies within microvilli via its ERM linkers (either directly or indirectly) in the organization of the preformed TCR assemblies within microvilli. It is not very likely that p-ERMs interact directly with the TCR $\alpha \beta$ intracellular regions, since they are very short (Alcover et al., 2018). They could also interact with other subunits $(\mathrm{CD} 3 \varepsilon, \mathrm{CD} 3 \gamma$, and TCR $\zeta$, which are associated with TCR $\alpha / \beta$ at the plasma membrane; Alcover et al., 2018). Other laboratories have described TCR $\zeta$ interaction with the actin cytoskeleton, as assessed by detergent insolubility assays (Caplan and Baniyash, 1996; Caplan et al., 1995; Rozdzial 
et al., 1995). We have failed in the past to detect an association of TCR complex subunits or T cell signaling molecules with ERMs by co-immunoprecipitation approaches. Lack of co-immunoprecipitation may be a sign of low-affinity interactions between TCR-CD3- $\zeta$ subunits, co-receptors, or signaling molecules and ERMs or their molecular partners but would not preclude a role of ezrin in TCR confinement on plasma membrane domains related to microvilli. ERM-dependent actin anchoring may form a chemical and a physical barrier for the diffusion of TCR molecules away from microvilli. This type of a barrier might not completely prevent lateral diffusion of TCR molecules. Indeed, single-particle tracking experiments on TCR components demonstrated lateral motion but found diffusion coefficients (Dushek et al., 2008; Favier et al., 2001) that are 100 times smaller than the typical diffusion coefficients of free membrane proteins (Fujiwara et al., 2016).

The connection of TCR components to the actin filaments inside microvilli also allows $T$ cells to exert significant forces on these components during the first few seconds following encounter of the APC, and these forces may stabilize the TCRMHC-peptide bonds, as suggested by recent biophysical measurements (Depoil and Dustin, 2014; Feng et al., 2017; Liu et al., 2016; Sibener et al., 2018). As the T cell interaction with the APC persists, the phosphorylated ERM linkers become inactivated by dephosphorylation (Faure et al., 2004) and release the connection of the cortical actin cytoskeleton and the plasma membrane in the vicinity of the TCR machineries. The TCR $\alpha \beta$ and its proximal signaling molecules likely use multiple ERM proteins as switchable phosphorylation-regulated linkers, which diffuse away from the tips of the microvilli they are located on following TCR activation and dephosphorylation.

Taken together, our results demonstrate that the pre-organization of the TCR machinery on microvilli depends on the intact anchorage to the actin cytoskeleton facilitated by ERM linkers. The pre-organization of TCR complexes and co-stimulatory molecules on T cell microvilli may have several advantages. First, the flexible structure and constant motion of microvilli likely make the search for antigens on APCs faster and more efficient (Cai et al., 2017). Indeed, recent work emphasized the importance of the initial encounter between the T cell and the APC and the fast signal generation that includes conformational changes in relevant proteins such as Lck (Philipsen et al., 2017), followed by phosphorylation of downstream kinases like ZAP-70 as well as calcium mobilization (Friedl and Bröcker, 2002; Henrickson et al., 2013; Marangoni et al., 2013). Second, the large surface area of microvilli accommodates a large number of membrane proteins. Third, the concentration of TCR molecules with their proximal signaling molecules on microvilli increases their avidity for cognate antigenic peptides on the APC and thereby facilitates TCR signal transmission. Indeed, recent reports highlight the ability of individual TCR microclusters to deliver local signals within seconds or a few minutes (Cai et al., 2017; Sibener et al., 2018; Taylor et al., 2017; Varma et al., 2006) prior to the formation of stable ISs that consist of large TCR supramolecular structures (Dustin and Choudhuri, 2016).

In conclusion, we demonstrated that rather than being randomly distributed on the $\mathrm{T}$ cell membrane, multiple proteins involved in the initial recognition and incorporation of antigenic signals are specifically pre-clustered on microvilli, which facilitates the initial recognition events underlying the TCR activation cascade. Upon recognition of cognate peptide/MHC complexes on APCs, one or more of these TCR machineries likely get released from their original assemblies within microvilli and together with a gradual collapse of the microvilli and additional remodeling of the actin cytoskeleton (Hui et al., 2015; VicenteManzanares and Sánchez-Madrid, 2004) promote the formation of stable immune synapses. Future work should focus on this putative TCR release process and help identify if and how dephosphorylation of ERM family members facilitates the redistribution of TCR machineries and the topographical alterations that enable them to drive optimal T cell activation.

\section{STAR $\star$ METHODS}

Detailed methods are provided in the online version of this paper and include the following:

- KEY RESOURCES TABLE

- LEAD CONTACT AND MATERIALS AVAILABILITY

- EXPERIMENTAL MODEL AND SUBJECT DETAILS

O Human T cells

O Jurkat $T$ cell culture

- METHOD DETAILS

Transfection

O ERK1/ERK2 kinase activation assay

- Cellular labeling with antibodies

- Labeling at $4{ }^{\circ} \mathrm{C}$ captures the bona fide resting state of T cells

O Sample preparation for microscopy

O TIRF setup

Reconstruction of 3D cell surfaces and detection of microvilli

Microvilli can be identified using L-selectin localization

- SLN measurement

O Drift correction

- Localization analysis

- Quantitative analysis of molecular distribution

Cluster Analysis

3D SLN setup

SEM Imaging

TEM imaging

- QUANTIFICATION AND STATISTICAL ANALYSIS

- DATA AND CODE AVAILABILITY

\section{SUPPLEMENTAL INFORMATION}

Supplemental Information can be found online at https://doi.org/10.1016/j. celrep.2020.02.069.

\section{ACKNOWLEDGMENTS}

We thank Drs. Sandeep Yadav, Alexander Vaskevich, and Yunmin Jung, as well as Mr. Francesco Roncato, of the Weizmann Institute of Science, for their kind advice and experimental help during the project. We also thank Dr. Keir Neuman $(\mathrm{NIH})$ for kindly sharing with us fluorescent nanodiamond samples. The SEM studies were conducted at the Electron Microscopy Unit of the Weizmann Institute of Science. G.H. is the incumbent of the Hilda Pomeraniec Memorial Professorial Chair. 


\section{AUTHOR CONTRIBUTIONS}

S.G., A.A., R.A., and G.H. designed research; S.G., V.D.B., L.T., E.S., E.K., T.D., and S.W.F. performed research; S.G. and G.H. analyzed data; and S.G., A.A., R.A., and G.H. wrote the paper.

\section{DECLARATION OF INTERESTS}

The authors declare no competing interests.

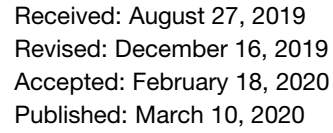

Received: August 27, 2019

Revised: December 16, 2019

Accepted: February 18, 2020

Published: March 10, 2020

\section{REFERENCES}

Alcover, A., Alarcón, B., and Di Bartolo, V. (2018). Cell biology of T cell receptor expression and regulation. Annu. Rev. Immunol. 36, 103-125.

Algrain, M., Turunen, O., Vaheri, A., Louvard, D., and Arpin, M. (1993). Ezrin contains cytoskeleton and membrane binding domains accounting for its proposed role as a membrane-cytoskeletal linker. J. Cell Biol. 120, 129-139.

Allenspach, E.J., Cullinan, P., Tong, J., Tang, Q., Tesciuba, A.G., Cannon, J.L., Takahashi, S.M., Morgan, R., Burkhardt, J.K., and Sperling, A.I. (2001). ERMdependent movement of CD43 defines a novel protein complex distal to the immunological synapse. Immunity 15, 739-750.

Arpin, M., Chirivino, D., Naba, A., and Zwaenepoel, I. (2011). Emerging role for ERM proteins in cell adhesion and migration. Cell Adhes. Migr. 5, 199-206.

Babich, A., Li, S., O'Connor, R.S., Milone, M.C., Freedman, B.D., and Burkhardt, J.K. (2012). F-actin polymerization and retrograde flow drive sustained PLC $\gamma 1$ signaling during T cell activation. J. Cell Biol. 197, 775-787.

Berryman, M., Franck, Z., and Bretscher, A. (1993). Ezrin is concentrated in the apical microvilli of a wide variety of epithelial cells whereas moesin is found primarily in endothelial cells. J. Cell Sci. 105, 1025-1043.

Bouchet, J., Del Río-Iñiguez, I., Vázquez-Chávez, E., Lasserre, R., AgüeraGonzález, S., Cuche, C., McCaffrey, M.W., Di Bartolo, V., and Alcover, A. (2017). Rab11-FIP3 regulation of Lck endosomal traffic controls TCR signal transduction. J. Immunol. 198, 2967-2978.

Bretscher, A., Edwards, K., and Fehon, R.G. (2002). ERM proteins and merlin: integrators at the cell cortex. Nat. Rev. Mol. Cell Biol. 3, 586-599.

Brown, M.J., Nijhara, R., Hallam, J.A., Gignac, M., Yamada, K.M., Erlandsen, S.L., Delon, J., Kruhlak, M., and Shaw, S. (2003). Chemokine stimulation of human peripheral blood T lymphocytes induces rapid dephosphorylation of ERM proteins, which facilitates loss of microvilli and polarization. Blood 102, 38903899.

Bunnell, S.C., Kapoor, V., Trible, R.P., Zhang, W., and Samelson, L.E. (2001). Dynamic actin polymerization drives $T$ cell receptor-induced spreading: a role for the signal transduction adaptor LAT. Immunity 14, 315-329.

Bunnell, S.C., Hong, D.I., Kardon, J.R., Yamazaki, T., McGlade, C.J., Barr, V.A., and Samelson, L.E. (2002). T cell receptor ligation induces the formation of dynamically regulated signaling assemblies. J. Cell Biol. 158, 1263-1275.

Burkhardt, J.K., Carrizosa, E., and Shaffer, M.H. (2008). The actin cytoskeleton in T cell activation. Annu. Rev. Immunol. 26, 233-259.

Cai, E., Marchuk, K., Beemiller, P., Beppler, C., Rubashkin, M.G., Weaver, V.M., Gérard, A., Liu, T.L., Chen, B.C., Betzig, E., et al. (2017). Visualizing dynamic microvillar search and stabilization during ligand detection by $\mathrm{T}$ cells. Science 356, eaal3118.

Caplan, S., and Baniyash, M. (1996). Normal T cells express two T cell antigen receptor populations, one of which is linked to the cytoskeleton via zeta chain and displays a unique activation-dependent phosphorylation pattern. J. Biol. Chem. 271, 20705-20712.

Caplan, S., Zeliger, S., Wang, L., and Baniyash, M. (1995). Cell-surface-expressed T-cell antigen-receptor zeta chain is associated with the cytoskeleton. Proc. Natl. Acad. Sci. USA 92, 4768-4772.
Davis, S.J., and van der Merwe, P.A. (2006). The kinetic-segregation model: TCR triggering and beyond. Nat. Immunol. 7, 803-809.

Delon, J., Kaibuchi, K., and Germain, R.N. (2001). Exclusion of CD43 from the immunological synapse is mediated by phosphorylation-regulated relocation of the cytoskeletal adaptor moesin. Immunity 15, 691-701.

Dempsey, G.T., Bates, M., Kowtoniuk, W.E., Liu, D.R., Tsien, R.Y., and Zhuang, X. (2009). Photoswitching mechanism of cyanine dyes. J. Am. Chem. Soc. 131, 18192-18193.

Depoil, D., and Dustin, M.L. (2014). Force and affinity in ligand discrimination by the TCR. Trends Immunol. 35, 597-603.

Dixon, P.M. (2014). Ripley's K function. In Encyclopedia of Environmetrics, A.H. El-Shaarawi and W.W. Piegorsch, eds. (John Wiley \& Sons), pp. 17961803.

Dushek, O., Mueller, S., Soubies, S., Depoil, D., Caramalho, I., Coombs, D., and Valitutti, S. (2008). Effects of intracellular calcium and actin cytoskeleton on TCR mobility measured by fluorescence recovery. PLoS ONE 3, e3913.

Dustin, M.L. (2014). What counts in the immunological synapse? Mol. Cell 54, 255-262.

Dustin, M.L., and Choudhuri, K. (2016). Signaling and polarized communication across the T cell immunological synapse. Annu. Rev. Cell Dev. Biol. 32, 303-325.

Eltsov, M., Dubé, N., Yu, Z., Pasakarnis, L., Haselmann-Weiss, U., Brunner, D., and Frangakis, A.S. (2015). Quantitative analysis of cytoskeletal reorganization during epithelial tissue sealing by large-volume electron tomography. Nat. Cell Biol. 17, 605-614.

Endesfelder, U., and Heilemann, M. (2015). Direct stochastic optical reconstruction microscopy (dSTORM). Methods Mol. Biol. 1251, 263-276.

Esensten, J.H., Helou, Y.A., Chopra, G., Weiss, A., and Bluestone, J.A. (2016) CD28 costimulation: from mechanism to therapy. Immunity 44, 973-988.

Faure, S., Salazar-Fontana, L.I., Semichon, M., Tybulewicz, V.L., Bismuth, G., Trautmann, A., Germain, R.N., and Delon, J. (2004). ERM proteins regulate cytoskeleton relaxation promoting T cell-APC conjugation. Nat. Immunol. 5, 272-279.

Favier, B., Burroughs, N.J., Wedderburn, L., and Valitutti, S. (2001). TCR dynamics on the surface of living T cells. Int. Immunol. 13, 1525-1532.

Fehon, R.G., McClatchey, A.I., and Bretscher, A. (2010). Organizing the cell cortex: the role of ERM proteins. Nat. Rev. Mol. Cell Biol. 11, 276-287.

Feng, Y., Brazin, K.N., Kobayashi, E., Mallis, R.J., Reinherz, E.L., and Lang, M.J. (2017). Mechanosensing drives acuity of $\alpha \beta$ T-cell recognition. Proc. Natl. Acad. Sci. USA 114, E8204-E8213.

Fernandes, R.A., Ganzinger, K.A., Tzou, J.C., Jönsson, P., Lee, S.F., Palayret, M., Santos, A.M., Carr, A.R., Ponjavic, A., Chang, V.T., et al. (2019). A cell topography-based mechanism for ligand discrimination by the T cell receptor. Proc. Natl. Acad. Sci. USA 116, 14002-14010.

Foti, M., Phelouzat, M.A., Holm, A., Rasmusson, B.J., and Carpentier, J.L. (2002). p56Lck anchors CD4 to distinct microdomains on microvilli. Proc. Natl. Acad. Sci. USA 99, 2008-2013.

Friedl, P., and Bröcker, E.B. (2002). TCR triggering on the move: diversity of T-cell interactions with antigen-presenting cells. Immunol. Rev. 186, 83-89.

Fritzsche, M., Fernandes, R.A., Chang, V.T., Colin-York, H., Clausen, M.P., Felce, J.H., Galiani, S., Erlenkämper, C., Santos, A.M., Heddleston, J.M., et al. (2017). Cytoskeletal actin dynamics shape a ramifying actin network underpinning immunological synapse formation. Sci. Adv. 3, e1603032.

Fujiwara, T.K., Iwasawa, K., Kalay, Z., Tsunoyama, T.A., Watanabe, Y., Umemura, Y.M., Murakoshi, H., Suzuki, K.G.N., Nemoto, Y.L., Morone, N., and Kusumi, A. (2016). Confined diffusion of transmembrane proteins and lipids induced by the same actin meshwork lining the plasma membrane. Mol. Biol. Cell 27, 1101-1119.

Gao, J., Wang, F., Liu, Y., Cai, M., Xu, H., Jiang, J., and Wang, H. (2015). Revealing the cellular localization of STAT1 during the cell cycle by super-resolution imaging. Sci. Rep. 5, 9045. 
Gautreau, A., Louvard, D., and Arpin, M. (2000). Morphogenic effects of ezrin require a phosphorylation-induced transition from oligomers to monomers at the plasma membrane. J. Cell Biol. 150, 193-203.

Goodfellow, H.S., Frushicheva, M.P., Ji, Q., Cheng, D.A., Kadlecek, T.A., Cantor, A.J., Kuriyan, J., Chakraborty, A.K., Salomon, A., and Weiss, A. (2015). The catalytic activity of the kinase ZAP-70 mediates basal signaling and negative feedback of the T cell receptor pathway. Sci. Signal. 8, ra49.

Grakoui, A., Bromley, S.K., Sumen, C., Davis, M.M., Shaw, A.S., Allen, P.M., and Dustin, M.L. (1999). The immunological synapse: a molecular machine controlling T cell activation. Science 285, 221-227.

Henrickson, S.E., Perro, M., Loughhead, S.M., Senman, B., Stutte, S., Quigley, M., Alexe, G., Iannacone, M., Flynn, M.P., Omid, S., et al. (2013). Antigen availability determines $\mathrm{CD}^{+} \mathrm{T}$ cell-dendritic cell interaction kinetics and memory fate decisions. Immunity 39, 496-507.

Hu, Y.S., Cang, H., and Lillemeier, B.F. (2016). Superresolution imaging reveals nanometer- and micrometer-scale spatial distributions of T-cell receptors in lymph nodes. Proc. Natl. Acad. Sci. USA 113, 7201-7206.

Hui, K.L., Balagopalan, L., Samelson, L.E., and Upadhyaya, A. (2015). Cytoskeletal forces during signaling activation in Jurkat T-cells. Mol. Biol. Cell 26, 685-695.

Jardine, L., Barge, D., Ames-Draycott, A., Pagan, S., Cookson, S., Spickett, G., Haniffa, M., Collin, M., and Bigley, V. (2013). Rapid detection of dendritic cell and monocyte disorders using CD4 as a lineage marker of the human peripheral blood antigen-presenting cell compartment. Front. Immunol. 4, 495.

Jensen, K.H.R., and Berg, R.W. (2016). CLARITY-compatible lipophilic dyes for electrode marking and neuronal tracing. Sci. Rep. 6, 32674.

Jung, Y., Riven, I., Feigelson, S.W., Kartvelishvily, E., Tohya, K., Miyasaka, M., Alon, R., and Haran, G. (2016). Three-dimensional localization of T-cell receptors in relation to microvilli using a combination of superresolution microscopies. Proc. Natl. Acad. Sci. USA 113, E5916-E5924.

Kaizuka, Y., Douglass, A.D., Vardhana, S., Dustin, M.L., and Vale, R.D. (2009). The coreceptor CD2 uses plasma membrane microdomains to transduce signals in T cells. J. Cell Biol. 185, 521-534.

Kim, H.R., Mun, Y., Lee, K.S., Park, Y.J., Park, J.S., Park, J.H., Jeon, B.N., Kim, C.H., Jun, Y., Hyun, Y.M., et al. (2018). T cell microvilli constitute immunological synaptosomes that carry messages to antigen-presenting cells. Nat. Commun. 9, 3630.

Klammt, C., and Lillemeier, B.F. (2012). How membrane structures control T cell signaling. Front. Immunol. 3, 291.

Lasserre, R., Charrin, S., Cuche, C., Danckaert, A., Thoulouze, M.I., de Chaumont, F., Duong, T., Perrault, N., Varin-Blank, N., Olivo-Marin, J.C., et al. (2010). Ezrin tunes T-cell activation by controlling Dlg1 and microtubule positioning at the immunological synapse. EMBO J. 29, 2301-2314.

Lillemeier, B.F., Pfeiffer, J.R., Surviladze, Z., Wilson, B.S., and Davis, M.M. (2006). Plasma membrane-associated proteins are clustered into islands attached to the cytoskeleton. Proc. Natl. Acad. Sci. USA 103, 18992-18997.

Lillemeier, B.F., Mörtelmaier, M.A., Forstner, M.B., Huppa, J.B., Groves, J.T., and Davis, M.M. (2010). TCR and Lat are expressed on separate protein islands on T cell membranes and concatenate during activation. Nat. Immunol. $11,90-96$.

Liu, Y., Blanchfield, L., Ma, V.P., Andargachew, R., Galior, K., Liu, Z., Evavold, B., and Salaita, K. (2016). DNA-based nanoparticle tension sensors reveal that T-cell receptors transmit defined $\mathrm{pN}$ forces to their antigens for enhanced fidelity. Proc. Natl. Acad. Sci. USA 113, 5610-5615.

Majstoravich, S., Zhang, J., Nicholson-Dykstra, S., Linder, S., Friedrich, W., Siminovitch, K.A., and Higgs, H.N. (2004). Lymphocyte microvilli are dynamic, actin-dependent structures that do not require Wiskott-Aldrich syndrome protein (WASp) for their morphology. Blood 104, 1396-1403.

Makgoba, M.W., Sanders, M.E., and Shaw, S. (1989). The CD2-LFA-3 and LFA-1-ICAM pathways: relevance to T-cell recognition. Immunol. Today 10, 417-422.
Malissen, B., and Bongrand, P. (2015). Early T cell activation: integrating biochemical, structural, and biophysical cues. Annu. Rev. Immunol. 33, 539-561

Marangoni, F., Murooka, T.T., Manzo, T., Kim, E.Y., Carrizosa, E., Elpek, N.M. and Mempel, T.R. (2013). The transcription factor NFAT exhibits signal memory during serial T cell interactions with antigen-presenting cells. Immunity 38 , 237-249.

McClatchey, A.I. (2014). ERM proteins at a glance. J. Cell Sci. 127, 3199-3204. Monks, C.R., Freiberg, B.A., Kupfer, H., Sciaky, N., and Kupfer, A. (1998) Three-dimensional segregation of supramolecular activation clusters in T cells. Nature 395, 82-86.

Nieuwenhuizen, R.P., Lidke, K.A., Bates, M., Puig, D.L., Grünwald, D., Stallinga, S., and Rieger, B. (2013). Measuring image resolution in optical nanoscopy. Nat. Methods 10, 557-562.

Nijhara, R., van Hennik, P.B., Gignac, M.L., Kruhlak, M.J., Hordijk, P.L., Delon, J., and Shaw, S. (2004). Rac1 mediates collapse of microvilli on chemokineactivated T Iymphocytes. J. Immunol. 173, 4985-4993.

Pageon, S.V., Tabarin, T., Yamamoto, Y., Ma, Y., Nicovich, P.R., Bridgeman, J.S., Cohnen, A., Benzing, C., Gao, Y., Crowther, M.D., et al. (2016). Functiona role of T-cell receptor nanoclusters in signal initiation and antigen discrimination. Proc. Natl. Acad. Sci. USA 113, E5454-E5463.

Philipsen, L., Reddycherla, A.V., Hartig, R., Gumz, J., Kästle, M., Kritikos, A., Poltorak, M.P., Prokazov, Y., Turbin, E., Weber, A., et al. (2017). De novo phosphorylation and conformational opening of the tyrosine kinase Lck act in concert to initiate T cell receptor signaling. Sci. Signal. 10, eaaf4736.

Razvag, Y., Neve-Oz, Y., Sajman, J., Reches, M., and Sherman, E. (2018). Nanoscale kinetic segregation of TCR and CD45 in engaged microvilli facilitates early $T$ cell activation. Nat. Commun. 9, 732.

Rea, R., Li, J., Dharia, A., Levitan, E.S., Sterling, P., and Kramer, R.H. (2004). Streamlined synaptic vesicle cycle in cone photoreceptor terminals. Neuron $41,755-766$

Ritter, A.T., Kapnick, S.M., Murugesan, S., Schwartzberg, P.L., Griffiths, G.M., and Lippincott-Schwartz, J. (2017). Cortical actin recovery at the immunological synapse leads to termination of lytic granule secretion in cytotoxic T Iymphocytes. Proc. Natl. Acad. Sci. USA 114, E6585-E6594.

Roh, K.H., Lillemeier, B.F., Wang, F., and Davis, M.M. (2015). The coreceptor CD4 is expressed in distinct nanoclusters and does not colocalize with T-cell receptor and active protein tyrosine kinase p56lck. Proc. Natl. Acad. Sci. USA 112, E1604-E1613.

Roose, J.P., Diehn, M., Tomlinson, M.G., Lin, J., Alizadeh, A.A., Botstein, D. Brown, P.O., and Weiss, A. (2003). T cell receptor-independent basal signaling via Erk and Abl kinases suppresses RAG gene expression. PLoS Biol. 1, E53. Rossboth, B., Arnold, A.M., Ta, H., Platzer, R., Kellner, F., Huppa, J.B., Brameshuber, M., Baumgart, F., and Schütz, G.J. (2018). TCRs are randomly distributed on the plasma membrane of resting antigen-experienced T cells. Nat. Immunol. 19, 821-827.

Rossy, J., Williamson, D.J., and Gaus, K. (2012). How does the kinase Lck phosphorylate the T cell receptor? Spatial organization as a regulatory mechanism. Front. Immunol. 3, 167.

Rossy, J., Owen, D.M., Williamson, D.J., Yang, Z., and Gaus, K. (2013) Conformational states of the kinase Lck regulate clustering in early $\mathrm{T}$ cell signaling. Nat. Immunol. 14, 82-89.

Roumier, A., Olivo-Marin, J.C., Arpin, M., Michel, F., Martin, M., Mangeat, P. Acuto, O., Dautry-Varsat, A., and Alcover, A. (2001). The membrane-microfilament linker ezrin is involved in the formation of the immunological synapse and in T cell activation. Immunity 15, 715-728.

Roybal, K.T., Mace, E.M., Clark, D.J., Leard, A.D., Herman, A., Verkade, P., Orange, J.S., and Wülfing, C. (2015). Modest interference with actin dynamics in primary $T$ cell activation by antigen presenting cells preferentially affects lamellal signaling. PLoS ONE 10, e0133231.

Rozdzial, M.M., Malissen, B., and Finkel, T.H. (1995). Tyrosine-phosphorylated $T$ cell receptor zeta chain associates with the actin cytoskeleton upon activation of mature T Iymphocytes. Immunity 3, 623-633. 
Rust, M.J., Bates, M., and Zhuang, X. (2006). Sub-diffraction-limit imaging by stochastic optical reconstruction microscopy (STORM). Nat. Methods 3, 793-795.

Santos, A.M., Ponjavic, A., Fritzsche, M., Fernandes, R.A., de la Serna, J.B., Wilcock, M.J., Schneider, F., Urbančič, I., McColl, J., Anzilotti, C., et al. (2018). Capturing resting T cells: the perils of PLL. Nat. Immunol. 19, 203-205. Schnitzbauer, J., Wang, Y., Zhao, S., Bakalar, M., Nuwal, T., Chen, B., and Huang, B. (2018). Correlation analysis framework for localization-based superresolution microscopy. Proc. Natl. Acad. Sci. USA 115, 3219-3224.

Schwarz, U.S., and Alon, R. (2004). L-selectin-mediated leukocyte tethering in shear flow is controlled by multiple contacts and cytoskeletal anchorage facilitating fast rebinding events. Proc. Natl. Acad. Sci. USA 101, 6940-6945.

Sezgin, E., Levental, I., Mayor, S., and Eggeling, C. (2017). The mystery of membrane organization: composition, regulation and roles of lipid rafts. Nat. Rev. Mol. Cell Biol. 18, 361-374.

Shaffer, M.H., Dupree, R.S., Zhu, P., Saotome, I., Schmidt, R.F., McClatchey, A.I., Freedman, B.D., and Burkhardt, J.K. (2009). Ezrin and moesin function together to promote T cell activation. J. Immunol. 182, 1021-1032.

Sharp, M.D., and Pogliano, K. (1999). An in vivo membrane fusion assay implicates SpollIE in the final stages of engulfment during Bacillus subtilis sporulation. Proc. Natl. Acad. Sci. U S A 96, 14553-14558.

Sherman, E., Barr, V., Manley, S., Patterson, G., Balagopalan, L., Akpan, I., Regan, C.K., Merrill, R.K., Sommers, C.L., Lippincott-Schwartz, J., and Samelson, L.E. (2011). Functional nanoscale organization of signaling molecules downstream of the T cell antigen receptor. Immunity 35, 705-720.

Sibener, L.V., Fernandes, R.A., Kolawole, E.M., Carbone, C.B., Liu, F., McAffee, D., Birnbaum, M.E., Yang, X., Su, L.F., Yu, W., et al. (2018). Isolation of a structural mechanism for uncoupling $T$ cell receptor signaling from peptideMHC binding. Cell 174, 672-687.e627.

Simons, K., and Sampaio, J.L. (2011). Membrane organization and lipid rafts. Cold Spring Harb. Perspect. Biol. 3, a004697.

Smoligovets, A.A., Smith, A.W., Wu, H.J., Petit, R.S., and Groves, J.T. (2012). Characterization of dynamic actin associations with $\mathrm{T}$-cell receptor microclusters in primary T cells. J. Cell Sci. 125, 735-742.

Soares, H., Henriques, R., Sachse, M., Ventimiglia, L., Alonso, M.A., Zimmer, C., Thoulouze, M.I., and Alcover, A. (2013). Regulated vesicle fusion generates signaling nanoterritories that control $T$ cell activation at the immunological synapse. J. Exp. Med. 210, 2415-2433.

Speck, O., Hughes, S.C., Noren, N.K., Kulikauskas, R.M., and Fehon, R.G. (2003). Moesin functions antagonistically to the Rho pathway to maintain epithelial integrity. Nature 421, 83-87.

Stephen, T.L., Wilson, B.S., and Laufer, T.M. (2012). Subcellular distribution of Lck during CD4 T-cell maturation in the thymic medulla regulates the T-cell activation threshold. Proc. Natl. Acad. Sci. USA 109, 7415-7420.
Stewart, M.P., Cabanas, C., and Hogg, N. (1996). T cell adhesion to intercellular adhesion molecule-1 (ICAM-1) is controlled by cell spreading and the activation of integrin LFA-1. J. Immunol. 156, 1810-1817.

Stock, K., Sailer, R., Strauss, W.S., Lyttek, M., Steiner, R., and Schneckenburger, H. (2003). Variable-angle total internal reflection fluorescence microscopy (VA-TIRFM): realization and application of a compact illumination device. J. Microsc. 211, 19-29.

Sundd, P., Gutierrez, E., Pospieszalska, M.K., Zhang, H., Groisman, A., and Ley, K. (2010). Quantitative dynamic footprinting microscopy reveals mechanisms of neutrophil rolling. Nat. Methods 7, 821-824.

Tamzalit, F., Wang, M.S., Jin, W., Tello-Lafoz, M., Boyko, V., Heddleston, J.M., Black, C.T., Kam, L.C., and Huse, M. (2019). Interfacial actin protrusions mechanically enhance killing by cytotoxic T cells. Sci. Immunol. 4, eaav5445.

Taniuchi, I. (2018). CD4 helper and CD8 cytotoxic T cell differentiation. Annu. Rev. Immunol. 36, 579-601.

Taylor, M.J., Husain, K., Gartner, Z.J., Mayor, S., and Vale, R.D. (2017). A DNAbased $T$ cell receptor reveals a role for receptor clustering in ligand discrimination. Cell 169, 108-119.e120.

Treanor, B., Depoil, D., Bruckbauer, A., and Batista, F.D. (2011). Dynamic cortical actin remodeling by ERM proteins controls BCR microcluster organization and integrity. J. Exp. Med. 208, 1055-1068.

Tsukita, S., and Yonemura, S. (1999). Cortical actin organization: lessons from ERM (ezrin/radixin/moesin) proteins. J. Biol. Chem. 274, 34507-34510.

van de Linde, S., Löschberger, A., Klein, T., Heidbreder, M., Wolter, S., Heilemann, M., and Sauer, M. (2011). Direct stochastic optical reconstruction microscopy with standard fluorescent probes. Nat. Protoc. 6, 991-1009.

Varma, R., Campi, G., Yokosuka, T., Saito, T., and Dustin, M.L. (2006). T cell receptor-proximal signals are sustained in peripheral microclusters and terminated in the central supramolecular activation cluster. Immunity 25, 117-127.

Vicente-Manzanares, M., and Sánchez-Madrid, F. (2004). Role of the cytoskeleton during leukocyte responses. Nat. Rev. Immunol. 4, 110-122.

von Andrian, U.H., Hasslen, S.R., Nelson, R.D., Erlandsen, S.L., and Butcher, E.C. (1995). A central role for microvillous receptor presentation in leukocyte adhesion under flow. Cell 82, 989-999.

Wilkins, A.L., Yang, W., and Yang, J.J. (2003). Structural biology of the cell adhesion protein CD2: from molecular recognition to protein folding and design. Curr. Protein Pept. Sci. 4, 367-373.

Williamson, D.J., Owen, D.M., Rossy, J., Magenau, A., Wehrmann, M., Gooding, J.J., and Gaus, K. (2011). Pre-existing clusters of the adaptor Lat do not participate in early T cell signaling events. Nat. Immunol. 12, 655-662. 


\section{STAR $\star M E T H O D S$}

\section{KEY RESOURCES TABLE}

\begin{tabular}{|c|c|c|}
\hline REAGENT or RESOURCE & SOURCE & IDENTIFIER \\
\hline \multicolumn{3}{|l|}{ Antibodies } \\
\hline Alexa 647-conjugated mouse anti-human TCR $\alpha \beta$ antibody & Biolegend (clone IP26) & Cat\# 306714; RRID: AB_528969 \\
\hline Purified anti-human TCR $\alpha \beta$ antibody & Biolegend (clone IP26) & Cat\# 306702; RRID: AB_314628 \\
\hline Alexa 647-conjugated mouse anti-human CD45 antibody & Biolegend (clone HI30) & Cat\# 304020; RRID: AB_493034 \\
\hline Alexa 647-conjugated anti-human CD62L antibody & Biolegend (clone DREG-56) & Cat\# 304818; RRID: AB_10719092 \\
\hline Alexa 647 anti-human CD3 antibody & Biolegend (clone HIT3a) & Cat\# 300322; RRID: AB_493693 \\
\hline Purified anti-human CD3 antibody & Biolegend (clone OKT3) & Cat\# 317302; RRID: AB_571927 \\
\hline 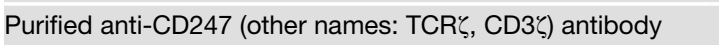 & Biolegend (clone 6B10.2) & Cat\# 644102; RRID: AB_2072963 \\
\hline Purified anti-LAT antibody & Biolegend (clone LAT1111) & Cat\# 623902; RRID: AB_2133118 \\
\hline Purified anti-Lck antibody & Biolegend (clone LCK-01) & Cat\# 628302; RRID: AB_2136336 \\
\hline Purified anti-human CD2 antibody & Biolegend (clone RPA-2.10) & Cat\# 300202; RRID: AB_314026 \\
\hline Purified anti-human CD4 antibody & Biolegend (clone OKT4) & Cat\# 317402; RRID: AB_571963 \\
\hline Purified anti-VSV-G epitope tag antibody & Biolegend (clone Poly29039) & Cat\# 903901; RRID: AB_2565035 \\
\hline $\begin{array}{l}\text { Anti-phospho-ezrin (Thr567)/radixin (Thr564)/moesin (Thr558) } \\
\text { (48G2) rabbit antibody }\end{array}$ & CST Technology & mAb \#3726; RRID: AB_10560513 \\
\hline \multicolumn{3}{|l|}{ Chemicals, Peptides, and Recombinant Proteins } \\
\hline Alexa Fluor 647 phalloidin & Thermo Fisher Scientific & Cat\# A22287; RRID: AB_2620155 \\
\hline Alexa Fluor 405 & Thermo Fisher Scientific & Cat\# A30000 \\
\hline Alexa Fluor 568 & Thermo Fisher Scientific & Cat\# A20103 \\
\hline Alexa Fluor 647 & Thermo Fisher Scientific & Cat\# A20106 \\
\hline \multicolumn{3}{|l|}{ Experimental Models: Cell Lines } \\
\hline Jurkat T cells & ATCC & TIB-152; RRID: CVCL_0367 \\
\hline \multicolumn{3}{|l|}{ Software and Algorithms } \\
\hline MATLAB & MathWorks & $\mathrm{N} / \mathrm{A}$ \\
\hline Origin & OriginLab Corporation & $\mathrm{N} / \mathrm{A}$ \\
\hline
\end{tabular}

\section{LEAD CONTACT AND MATERIALS AVAILABILITY}

Further information and requests for resources and reagents should be directed to and will be fulfilled by the Lead Contact, Shirsendu Ghosh (email: Shirsendu.ghosh@weizmann.ac.il). This study did not generate new unique reagents.

\section{EXPERIMENTAL MODEL AND SUBJECT DETAILS}

\section{Human T cells}

T cells were isolated from both male and female healthy volunteer donors. The WIS IRB, appointed by the President of the Weizmann Institute, has reviewed all the experimental protocols involved in this study in accordance with the Israeli law, NIH guidelines and the Common Rule of ethics regarding biomedical and behavioral research involving human subjects in the United States (Title 45 CFR 46). To isolate human peripheral T lymphocytes, de-identified whole blood from healthy donors was citrate-anticoagulated, followed by dextran sedimentation and Ficoll (Sigma) gradient separation. To remove B cells, a nylon wool column (Unisorb) was used. After incubating the cells in a complete RPMI growth medium for $>2 \mathrm{~h}$, only the non-adherent fraction of cells was collected to a new plate (this step resulted in $\sim 90 \%$ CD3+ T lymphocytes). To generate effector T cells, the cells were stimulated on an anti-CD3/anti-CD28 antibody-coated plate for $2 \mathrm{~d}$. After that, the effector cells were cultured in a complete RPMI growth medium that contained IL-2 $(350 \mathrm{U} / \mathrm{mL})$ and 2-mercaptoethanol $(50 \mu \mathrm{M})$ for 7-14 d.

\section{Jurkat T cell culture}

Jurkat clone E6.1 cells were grown in RPMI media containing 10\% fetal bovine serum (FBS), $10 \mathrm{mM} \mathrm{HEPES,} 100$ unit/ml penicillin, $100 \mu \mathrm{g} / \mathrm{ml}$ streptomycin and $2 \mathrm{mM} \mathrm{L-glutamine} \mathrm{in} \mathrm{an} \mathrm{atmosphere} \mathrm{of} 5 \%(\mathrm{v} / \mathrm{v}) \mathrm{CO} 2$ enriched air at $37^{\circ} \mathrm{C}$. 


\section{METHOD DETAILS}

\section{Transfection}

Jurkat E6.1 cells were washed in PBS without $\mathrm{Ca}^{2+}$ and $\mathrm{Mg}^{2+}$. They were then re-suspended in Neon resuspension buffer $\mathrm{R}$ (ThermoFisher Scientific) at $1 \times 10^{8} \mathrm{cells} / \mathrm{ml}$, and mixed with plasmid DNA (20 $\left.\mu \mathrm{g} / \mathrm{sample}\right)$ expressing either the $\mathrm{N}$-terminal or the C-terminal ezrin domain tagged with a VSV-G epitope (a kind gift from Dr. M. Arpin; Algrain et al., 1993). 100 $\mu$ cells were electroporated with three $1400 \mathrm{~V}$ pulses, $10 \mathrm{~ms}$ each, using a Neon transfection system (ThermoFisher Scientific). Cells were transferred to a RPMI1640 medium with Glutamax-I medium (GIBCO/ThermoFisher Scientific), supplemented with 10\% fetal bovine serum without antibiotics and cultured overnight at $+37^{\circ} \mathrm{C}$ in $5 \% \mathrm{CO} 2$.

\section{ERK1/ERK2 kinase activation assay}

Jurkat cells were transfected either with an empty vector or with the N-ter ezrin expression plasmid as described above. The day after, cells were collected, washed and mixed with Raji cells, either untreated or pre-loaded with bacterial superantigen (staphylococcal enterotoxin E, SEE, Toxin Technology, Inc.; $15 \mu \mathrm{g} / \mathrm{ml}$;). After incubation for $10 \mathrm{~min}$ at $37^{\circ} \mathrm{C}$, cells were fixed in $4 \%$ paraformaldehyde for $15 \mathrm{~min}$, washed twice in PBS then permeabilized with ice-cold methanol and left overnight at $-20^{\circ} \mathrm{C}$. Cells were then washed twice in PBS + 0.5\% BSA (FACS buffer) and stained with an anti-VSV-G monoclonal antibody (clone P5D4, purified from ascites), to assess the expression level of the N-ter ezrin, and anti-pERK1/2 rabbit antibodies (Cell Signaling Technology; ref. \#9101) to assess Erk1/2 kinase activation. (This antibody is specific for the phosphorylated Thr202/Tyr204 residues of activated Erk1/2, which are a hallmark of Erk1/2 kinase activation.). Samples were then washed twice in the FACS buffer and incubated with anti-mouse IgG1-PE (BD Biosciences, ref.\#550083) and anti-rabbit IgG-AlexaFluor647 (ThermoFisher Scientific, ref. \#A21245) conjugates. Finally, cells were washed, resuspended in the FACS buffer and analyzed with a MacsQuant flow cytometer (Miltenyi Biotech). Data analysis was performed using FlowJo 10 (FlowJo, LLC). Statistical significance was assessed with a one-way ANOVA test using GraphPad Prism software.

\section{Antibody labeling}

Unlabeled antibodies were labeled with Alexa Fluor 405, Alexa Fluor 568, Alexa Fluor 647 according to need. For this, unlabeled antibody molecules in PBS buffer were reacted with the NHS ester of the corresponding dye in a 1:10 ratio in presence of $0.1 \mathrm{M}$ sodium bicarbonate buffer for $1 \mathrm{~h}$ at room temperature in the dark. Micro Bio-Spin column with Bio-Gel P-30 (Bio-Rad) was used to remove the unlabeled dye molecules.

\section{Cellular labeling with antibodies}

A suspension of Jurkat or effector T cells was washed with $5 \mathrm{mM}$ EDTA/PBS for 5 min by centrifugation at $4^{\circ} \mathrm{C}$. The cells were incubated in a blocking solution ( $1 \% \mathrm{BSA}, 5 \mathrm{mM}$ EDTA, $0.05 \% \mathrm{~N}_{3} \mathrm{Na}$, PBS) on ice for $10 \mathrm{~min}$. For labeling of surface molecules, the cells were treated with antibodies (10-20 $\mu \mathrm{g} / \mathrm{mL}$ according to the antibody) for 20-60 min on ice. After washing the cells twice with $5 \mathrm{mM}$ EDTA/PBS by centrifugation at $4{ }^{\circ} \mathrm{C}$, they were fixed with a fixation buffer $[4 \%$ (wt/vol) paraformaldehyde, $0.2 \%-0.5 \%$ glutaraldehyde, $2 \%$ (wt/vol) sucrose, $10 \mathrm{mM}$ EGTA, and $1 \mathrm{mM}$ EDTA, PBS] in suspension for $2 \mathrm{~h}$ on ice. The fixative was washed twice with PBS by centrifugation. The cell membrane was then stained with FM143FX (Invitrogen; $5 \mu \mathrm{g} / \mathrm{mL}$ ) for 30 min on ice. We chose this dye as it is known to label membranes homogeneously (Jensen and Berg, 2016; Rea et al., 2004; Sharp and Pogliano, 1999). To verify this we treated FM143FX-labeled Jurkat T cells so that they spread over a glass surface such that their microvilli structure was lost. We observed homogeneous intensity of FM143FX throughout the cell membrane in TIRFM images (Figure S1V). This was contrasted with the observed images of cells that were fixed in solution (Figure S1W), which were the input into our analysis of microvilli structure. Following staining with FM143FX, another fixation for 30 min on ice was performed and fixatives were washed twice at $4^{\circ} \mathrm{C}$ with $\mathrm{PBS}$ by centrifugation. Cells were suspended in PBS and were kept at $4^{\circ} \mathrm{C}$. These cells were then directly used for super-resolution mapping of the receptors/adhesion molecule of interest. We verified that the procedure above, involving fixation in solution at $4{ }^{\circ} \mathrm{C}$, captures the true resting state of the cells (see details below).

For intracellular staining of signaling proteins, cells were first fixed with a fixation buffer [ $4 \%$ (wt/vol) paraformaldehyde, $0.2 \%-0.5 \%$ glutaraldehyde, $2 \%$ (wt/vol) sucrose, $10 \mathrm{mM} \mathrm{EGTA}$, and $1 \mathrm{mM}$ EDTA, PBS] in suspension for $2 \mathrm{~h}$ on ice. The fixative was washed twice with PBS by centrifugation. The cell membrane was then stained with FM1-43FX for 30 min on ice. Another fixation for 30 min on ice was performed and fixatives were washed twice at $4^{\circ} \mathrm{C}$ with PBS by centrifugation. Cells were then incubated in a permeabilization buffer $\left(0.05 \%\right.$ saponin and $1 \%$ BSA in PBS) along with the antibody $(10 \mu \mathrm{g} / \mathrm{mL})$ at $4^{\circ} \mathrm{C}$. Incubation time varied according to the antibody. After that, cells were washed twice at $4^{\circ} \mathrm{C}$ with PBS by centrifugation. Cells were suspended in PBS and were kept at $4^{\circ} \mathrm{C}$. To rule out alteration of the morphology of Jurkat $T$ cells by these procedures, we imaged fixed cells with SEM (Figures 1A and 1B). We found that the microvilli-dominated surface structure of Jurkat cells was intact.

For actin labeling, Jurkat cells were washed with the cytoskeleton buffer $(50 \mathrm{mM}$ imidazole, $50 \mathrm{mM} \mathrm{KCl}, 0.5 \mathrm{mM} \mathrm{MgCl} 2,0.1 \mathrm{mM}$ EDTA, and $1 \mathrm{mM} \mathrm{EGTA} \mathrm{(pH} \mathrm{6.8)),} \mathrm{incubated} \mathrm{for} 30 \mathrm{~min}$ at room temperature and then fixed with a fixation buffer [4\% (wt/vol) paraformaldehyde, $0.2 \%-0.5 \%$ glutaraldehyde in cytoskeleton buffer] in suspension for $2 \mathrm{~h}$ on ice. After washing the cells with PBS, the cell membrane was labeled with FM1-43FX for $30 \mathrm{~min}$ on ice. Cells were then incubated in a permeabilization buffer (0.05\% saponin and $1 \%$ BSA in PBS) along with the Alexa Fluor 647 phalloidin ( 1 unit $/ \mathrm{mL}$ ) at $4^{\circ} \mathrm{C}$. They were washed twice at $4^{\circ} \mathrm{C}$ with PBS by centrifugation and immediately imaged. 
For dual-color super resolution microscopy, two different proteins were labeled sequentially, using the same protocol described above.

For imaging studies with dominant negative ERM transfected Jurkat cells, TCR $\alpha \beta$ was labeled on live cells that were then fixed. The membrane was labeled with FM143FX and cells were fixed again using the same protocol described above. The cells were then incubated in a permeabilization buffer (0.05\% saponin and 1\% BSA in PBS) along with the Alexa Fluor 405 labeled anti-VSV-G epitope tag antibody $(10 \mu \mathrm{g} / \mathrm{mL})$ at $4^{\circ} \mathrm{C}$. The cells were washed twice at $4^{\circ} \mathrm{C}$ with PBS by centrifugation, suspended in PBS and kept at $4{ }^{\circ} \mathrm{C}$.

Labeling at $4^{\circ} \mathrm{C}$ captures the bona fide resting state of $\mathrm{T}$ cells

Cells used in this work were fixed in solution in order to guarantee that the true resting state of the cells is obtained and avoid any activation due to interaction with the surface (Santos et al., 2018). However, even in solution cells might be activated due to interaction with some antibodies at physiological temperature $\left(37^{\circ} \mathrm{C}\right)$. We therefore elected to perform labeling at $4^{\circ} \mathrm{C}$. To verify that the lower temperature does not create any labeling artifacts, we performed the following experiments. First, we the compared staining of T cells with anti Alexa-647 labeled L-selectin and anti-CD 45 antibodies at $4{ }^{\circ} \mathrm{C}$ and $37^{\circ} \mathrm{C}$, following fixation at the same temperature in each case (Figure S1). We found that at both temperatures L-selectin was concentrated on microvilli, (Jung et al., 2016; von Andrian et al., 1995) while CD45 was distributed uniformly throughout the membrane. (Cai et al., 2017; Fernandes et al., 2019; Jung et al., 2016) Next, we stained T cells with Alexa- 647 labeled anti human TCR $\alpha \beta$ antibodies at the two temperatures. At $4^{\circ} \mathrm{C}$ the structure of microvilli on almost all the T cells was intact, and the TCR $\alpha \beta$ molecules localized on them (Figure S1T). On the other hand, at $37^{\circ} \mathrm{C}$ most of the cells lost their microvillar structures, likely due to stimulation by the antibodies. We did find a few $\mathrm{T}$ cells that still presented intact microvillar structure, and in these cells, TCR $\alpha \beta$ was localized on the microvilli (Figure S1U), similar to the observation at $4^{\circ} \mathrm{C}$. Thus labeling of cells with the TCR $\alpha \beta$ antibody had to be done at $4^{\circ} \mathrm{C}$ to prevent cellular activation. For other antibodies (i.e., anti- L-selectin and anti-CD45) labeling could be done at both $4^{\circ} \mathrm{C}$ and $37^{\circ} \mathrm{C}$, which gave similar results. Thus, it is evident that $\mathrm{T}$ cell labeling and fixation at $4^{\circ} \mathrm{C}$ in solution helps capturing the bona fide resting state of the cells for all antibodies.

\section{Sample preparation for microscopy}

Glass-bottom Petri dishes were cleaned with $1 \mathrm{M} \mathrm{NaOH}$ (Fluka) for $40 \mathrm{~min}$, then coated with PLL (0.01\%; Sigma) for 40 min and washed with PBS. $100 \mu \mathrm{l}$ of the labeled cell solution in PBS was placed in the Petri dish and cells were allowed to settle on the PLL surface for 10 minutes. The PBS buffer was then exchanged with a freshly prepared "blinking buffer" [50 mM cysteamine (Sigma), $0.5 \mathrm{mg} / \mathrm{mL}$ glucose oxidase (Sigma), $40 \mu \mathrm{g} / \mathrm{mL}$ catalase (Sigma), 10\% (wt/vol) glucose (Sigma), $93 \mathrm{mM} \mathrm{Tris \cdot HCl,} \mathrm{PBS} \mathrm{buffer}$ (pH 7.5-8.5)] and the sample was kept for 30 minutes before imaging was conducted.

\section{TIRF setup}

Our microscope setup was described in detail in our previous publication (Jung et al., 2016). Briefly, the setup had three different lasers sources (405 nm; Toptica iBEAM-SMART-405-S, $532 \mathrm{~nm}$; COBOLT SambaTM $50 \mathrm{~mW}$ and $642 \mathrm{~nm}$; Toptica iBEAMSMART-640-S). A series of dichroic beam splitters (z408bcm, z532bcm; Chroma) and an objective lens (M-20 ×; N.A., 0.4; Newport) were used to couple the lasers into a polarization-maintaining single-mode fiber. This fiber was connected to an acousto-optic tunable filter (AOTFFnc-VIS-TN-FI; AA Opto-Electronic), which was used to separately modulate each excitation beam. A polarizer (GT10-A; Thorlabs) for each laser was used to modulate the polarization to maximize coupling efficiency. We controlled the power of each laser either manually by adjustment of a half-wave plate (WPH05M; Thorlabs) positioned after a polarizer or by the computer. Achromatic lenses (01LAO773, 01LAO779; CVI Melles Griot) were utilized to expand and collimate the first-order output beams from the AOTF to a diameter of $6 \mathrm{~mm}$. An achromatic focusing lens ( $\mathrm{f}=500 \mathrm{~mm}$;LAO801; CVI Melles Griot) was employed to focus the expanded laser beams at the back focal plane of the microscope objective lens (UAPON $100 \times$ OTIRF; N.A., 1.49; Olympus). To achieve total internal reflection at the sample we shifted the position of the focused beam from the center of the objective to its edge. A quad-edge super-resolution laser dichroic beam splitter (Di03-R405/488/532/635-t1-25x36) was utilized to separate fluorescence emitted from the excitation. It was then coupled out from the side port of the microscope (Olympus IX71). Notch filters (NF01405/488/532/635 StopLine Quad-notch filter and ZET635NF; Semrock) were used to block the residual scattered laser light. A single EMCCD camera (iXonEM +897 back-illuminated; Andor) was employed in a dual-view mode: Spectrally separated images were projected onto the two halves of the CCD chip. Our setup had a final magnification of $240 \times$, which resulted in a pixel size of $66.67 \mathrm{~nm}$.

As discussed in the Results, we imaged molecules on two different planes within each sample. It could be argued that due to the exponentially decaying intensity of the TIRF laser field, the detection of molecules might be biased to those closer to the glass surface. To check this issue we imaged two different glass surface uniformly coated with Alexa-647 dye molecules (Figures S1M-S1O). In the first experiment, the dye molecules were uniformly coated directly on the glass surface. Using the TIRF microscope, we captured videos on at least 10 different regions $(8.5 \mu \mathrm{m} \times 8.5 \mu \mathrm{m}$ each) of the glass surface, focusing right at the interface with the glass substrate (Figure S1M). Using photobleaching steps to count molecules, we found that the average number of molecules detected within a region was $\sim 26.4 \pm 1.5$ (Figure S1O). In the second experiment, the glass surface was first coated with a $500 \mathrm{~nm}$ thick layer of the polymer MY-133 MC (MY Polymers, Israel), whose refractive index (1.328) is almost same as that of water. Dye molecules were then coated uniformly on top of the polymer layer. We now captured videos while focusing $500 \mathrm{~nm}$ away from the glass substrate. The average number of molecules detected within a region was in this case $25.8 \pm 2.1$ (Figures S1N-S1O). Our dualplane SLN technique was thus shown to detect molecules even when they are $500 \mathrm{~nm}$ away from glass surface. This rules out 
the possibility of a biased detection of molecules closer to glass surface. Moreover, we demonstrated that CD45 molecules are randomly and homogeneously distributed on the T cell membrane. This finding (reported originally in our 2016 paper and also by two additional, independent studies (Cai et al., 2017; Fernandes et al., 2019), would not be possible in case our microscopy preferentially identified molecules close to the glass. Taken together, these two experiments point to our ability to distinguish correctly the distribution of molecules on microvilli and cell body of T cells.

\section{Reconstruction of 3D cell surfaces and detection of microvilli}

The methodology for 3D surface reconstruction and detection of microvilli from TIRF images taken at a series of angles was described in detail in reference (Jung et al., 2016). Briefly, we recorded TIRF images of cells at a series of angles of incidence under weak illumination of a 532-nm laser. The pixel with maximum intensity at a particular angle of incidence $\left(I_{\max }(\theta)\right)$ should be the closest one to the glass surface. To calculate the relative axial distance $(\delta z)$ of each point on the cell surface we used the following equation;

$$
\delta z=\ln \left(I_{\max }(\theta) / I(\theta)\right) / d(\theta)
$$

(Equation 1)

where $d(\theta)$ represents penetration depth of the TIRF evanescent field with an angle of incidence $\theta$, which may be calculated from the following equation:

$$
d(\theta)=(\lambda / 4 \pi)\left(\eta_{1}^{2} \sin ^{2} \theta-\eta_{2}^{2}\right)
$$

In this equation $\lambda$ stands for the excitation wavelength $(532 \mathrm{~nm})$, and $\eta_{1}$ and $\eta_{2}$ represent the refractive index of the immersion oil (1.52) and blinking buffer (1.35), respectively.

To find the location of the tips of microvilli, we developed an appropriate algorithm based on MATLAB. First, the "Laplacian of a Gaussian" (LoG) filter was applied to the TIRF images, and the processed images were then converted to binary images by setting a threshold. The binary images were segmented using the function "bwlabel." To include the maximum number of microvilli, the binary image acquired from the data recorded at the smallest angle of incidence was considered for segmentation first, and then data from the image recorded at the largest angle of incidence was combined to separate individual microvilli. Finally, segmented areas obtained from images taken at angles $65.5^{\circ}, 66.8^{\circ}$, and $68.2^{\circ}$ were combined and the mean of the $\delta z$ of each pixel was calculated and used to generate the LocTips map (Figure S1). For a more detailed description the reader is referred to our previous publication (Jung et al., 2016, page E5922, Sections: 'Reconstruction of 3D Cell Surfaces' and 'Constructing LocTips Maps.').

\section{Microvilli can be identified using L-selectin localization}

We sometimes observed elongated bulging structures (0.5-1 $\mu$ long) in our TIRF images (Figure 1F). We attributed these structures to microvilli that lie down horizontally on the glass surface. In fact, microvilli that are flattened against the cell body can be observed even in SEM images, as demonstrated in Figures S1J and S1K (see red arrows). To further validate the identity of the elongated bulging structures, we carefully studied L-selectin localization relative to these structures. It is well known that L-selectin exclusively localizes on the microvilli of resting lymphocyte cells(Jung et al., 2016; von Andrian et al., 1995), which makes this surface molecule a most reliable marker of microvilli. Labeling Jurkat cells with anti-L-selectin antibodies, we observed that ridges were enriched with L-selectin (black arrow in Figure S1L), confirming their identity as microvilli lying on their side.

\section{SLN measurement}

Alexa-647 and Alexa-568 dyes were used for SLN measurements. These dyes can be converted to a dark state upon illumination with a very high intensity laser of the appropriate wavelength. In the presence of a buffer containing $\beta$-mercaptoethylamine together with glucose oxidase/catalase (an oxygen-scavenging system (Dempsey et al., 2009; van de Linde et al., 2011)), a small fraction of the dye molecules may be switched back at any moment of time. Thus, individual molecules appear separately in consecutive recording frame. This phenomenon helps to detect the location of a molecule with precision well below the diffraction limit. For all SLN measurements, the laser beam incident angle was $66.8^{\circ}$. For each focal plane, we recorded 28,000 frames, in 7 series of movies (each containing 4000 frames). We used a piezo stage (PI nano Z-Piezo slide scanner; PI) to record SLN movies at the $0 \mathrm{~nm}$ and $-400 \mathrm{~nm}$ focal planes. The measurement at two different planes ensured that proteins localized on membrane regions situated somewhat further from the surface due to the length of microvillar protrusions would not be overlooked. In fact, given the significant depth of focus, and given the high laser power used in the super-resolution measurements, focusing on the -400 nm plane allowed us to better observe cell body regions, while still obtaining signals from molecules on microvilli as well.

\section{Drift correction}

Since each SLN experiment involved a large number of separate movies, we had to correct them for microscope drift during the measurement. To that end, we recorded TIRF reference images of the cell membrane before and after each SLN movie underweak illumination of a 532-nm laser (10-20 $\mu \mathrm{W})$. We performed a 2D cross-correlation of each reference TIRF image with the previous reference image for identifying the drift level. For dual-color SLN, we used fluorescent nanodiamonds as fiducial points for drift correction. 
The drift typically found within one SLN movie was not larger than $35 \mathrm{~nm}$, based on either method. Following multiple such corrections, we could estimate that the accuracy of the registration over time (i.e., the error introduced after correction by the above method) was as good as $4 \mathrm{~nm}$.

To register the $532 \mathrm{~nm}$ and $647 \mathrm{~nm}$ SLN channels, we used the following procedure. We realized that there is some leak from the $532 \mathrm{~nm}$ channel into the $647 \mathrm{~nm}$ channel (this leak is not there when we take the true $647 \mathrm{~nm}$ image, as the $532 \mathrm{~nm}$ laser is then off). We therefore cross-correlated the leaked image in the $647 \mathrm{~nm}$ channel with the original $532 \mathrm{~nm}$ image, and used the cross-correlation to determine the shift between the two images and correct for it. From repeats of this procedure, we could estimate an excellent registration accuracy of $\sim 5 \mathrm{~nm}$.

\section{Localization analysis}

Detailed molecular localization procedures were provided in reference (1). Briefly, a thresholding step was used to identify individual emitters. They were then fitted to a 2D Gaussian function to obtain their $x$ and y coordinates and the widths of their point-spread functions in the $x$ and $y$ directions. We obtained a narrow distribution of widths in these measurements. Only those molecules whose widths were within \pm 3 SD of the mean were considered. Our methodology strictly discriminates against 'out-of-focus' events. For a detailed explanation we refer the reader to our previous publication (Jung et al., 2016, page E5923, Section: 'Dual-Plane SLN', $2^{\text {nd }}-3^{\text {rd }}$ Paragraph; Figure S3). Briefly, the discrimination is based on the widths of the fitted Gaussian functions: out-of-focus molecules have a larger width, and by introducing a threshold on the width parameter in the localization analysis we can readily remove them. Therefore, when one plane is sampled (either $0 \mathrm{~nm}$ or $-400 \mathrm{~nm}$ ), molecules that are far from this plane are discarded by the analysis and do not appear in the image.

The average localization uncertainty in $\mathrm{x}-\mathrm{y}$ was estimated to be $\sim 11 \mathrm{~nm}(\mathrm{FWHM})$, while the image resolution, calculated based on Fourier ring correlation analysis of images (Nieuwenhuizen et al., 2013), was $\sim 30 \mathrm{~nm}$. (Note that the latter depends both on the localization uncertainty and on the density of labeled molecules.) It should be noted here that the number of molecules in the $-400 \mathrm{~nm}$ plane was always smaller than that in the $0 \mathrm{~nm}$ plane because we recorded 28,000 super-resolution frames from the $0 \mathrm{~nm}$ plane first, so that when we recorded from the $-400 \mathrm{~nm}$ plane multiple molecules had already photobleached. In fact, when we reversed the order of acquisition of data from the two planes, we found that the relative number of molecules identified in the two planes was inverted. However, this has no effect on the results themselves, as we did not count the molecules, but rather observed their spatial distribution. Indeed, in this work we were not interested in counting the absolute number of molecules but rather in their distribution on the cell surface. Therefore, fluorophore blinking during the measurement also did not affect our conclusions. We explicitly verified that the artifactual appearance of nanoclusters due to blinking does not affect our results using analysis based on Ripley's K function (see section on Cluster Analysis below; Dixon, 2014; Gao et al., 2015; Roh et al., 2015; Figure S5).

\section{Quantitative analysis of molecular distribution}

To analyze the distribution of each membrane protein, we segmented the membrane area of each cell into microvilli (MV) regions and non-microvilli or cell-body (CB) regions using the analysis described in our previous work (Jung et al., 2016). We then calculated the percentage of molecules on microvilli regions and on cell body regions (Figures S6A-S6D) of each cell.

We also determined the cumulative fractional increase of the number of molecules of a specific protein on each cell as a function of the distance from the central region of each microvillus (Figures S6E-S6G). To this end, the central region of each microvillus was defined as the region that is not more than $20 \mathrm{~nm}$ from the microvillar tip, which is the pixel of the minimum $\delta z$ value. We then used the 'boundary' function of MATLAB to encapsulate this central region (Figure S6F), which could take different shapes, depending on the shape of the specific microvillus and how it sat with respect to the surface. We then plotted concentric closed curves of a similar shape and increasing size (Figure S6G), and calculated the number of molecules in each concentric structure, from which we obtained the cumulative fractional increase. This value was normalized by the cumulative fractional increase of the area, to obtain the

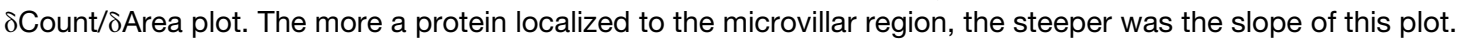

\section{Cluster Analysis}

To estimate clustering of membrane proteins, we used Ripley's K-function (Dixon, 2014; Gao et al., 2015; Roh et al., 2015), which calculates the number of molecules within distance $r$ of a randomly chosen molecule:

$$
K(r)=\frac{A}{N^{2}} \sum_{i=1}^{N} \sum_{j=1, j \neq i}^{N} \delta\left(r_{i j} \leq r\right),
$$

where A represents the image area of interest, $\mathrm{N}$ is the total number of localizations in the area of interest, and $\delta\left(r_{i j} \leq r\right)$ equals 1 if the distance between the two molecules $\left(r_{i j}\right)$ is smaller or equal to $r$. Molecules were only included if they were at least at a distance $r$ away from the edge of the image. We used a linear transformation of the K-function to get an estimate of maximum cluster sizes as follows:

$$
H(r)=\sqrt{\frac{K(r)}{r}}-r \text {. }
$$


For a random distribution of particles, $\mathrm{H}(\mathrm{r})$ equals zero. Positive values of $\mathrm{H}(\mathrm{r})$ represent clustering of particles. The maximum amplitude of $\mathrm{H}(\mathrm{r})$ represents the size of the largest clusters (Gao et al., 2015). To verify our cluster analysis protocol, we simulated clusters with sizes normally distributed around a known value. We then performed the cluster analysis on the simulated data. The maximum cluster size calculated from the cluster analysis on the simulated data agreed well with the known maximum cluster size.

\section{D SLN setup}

Three-dimensional super resolution images of the actin cytoskeleton were collected on a Vutara SR352 (Bruker) microscope based on the single-molecule localization biplane technology, using a $60 x$ silicon oil immersion objective (1.3 NA). Alexa Fluor 647 phalloidin labeled actin was excited using $640 \mathrm{~nm}$ laser $(5 \mathrm{~kW} / \mathrm{cm} 2)$, and 45,000 frames were acquired with an acquisition time of $20 \mathrm{~ms}$ per frame. Imaging was performed in the presence of the imaging buffer ( $7 \mu \mathrm{M}$ glucose oxidase (Sigma), $56 \mathrm{nM}$ catalase (Sigma), $5 \mathrm{mM}$ cysteamine (Sigma), $50 \mathrm{mM}$ Tris, $10 \mathrm{mM} \mathrm{NaCl}, 10 \%$ glucose, $\mathrm{pH}$ 8). Data were analyzed and visualized by the Vutara SRX software.

\section{SEM Imaging}

Please refer to our previous publication for detailed procedures (Jung et al., 2016). Briefly, we fixed Jurkat cells using 4\% (wt/vol) paraformaldehyde, $0.5 \%$ glutaraldehyde, $2 \%$ (wt/vol) sucrose, $10 \mathrm{mM}$ EGTA, and $1 \mathrm{mM}$ EDTA in PBS for $2 \mathrm{~h}$ on ice. We placed the fixed cells on a PLL coated coverslip. Different concentrations of ethanol were used to dehydrate the cells. Then the samples were dried in a BAL-TEC CPD 030 critical point drier. We placed the samples on a carbon tape and coated with carbon (Edward; Auto306) or sputter-coated with gold-palladium (Edward; S150). A Ultra 55 SEM (Zeiss) was used to image the samples.

\section{TEM imaging}

Sample preparation was adapted from Eltsov et al. (2015). Cells were concentrated by centrifugation. A drop of the pellet was placed on an aluminum disc (Engineering Office M. Wohlwend $\mathrm{GmbH}$, Sennwald, Switzerland) with a $100 \mu \mathrm{m}$ deep cavity and covered with a flat disc. The sample was then frozen in a HPM 010 high-pressure freezing machine (Bal-Tec, Liechtenstein). Cells were subsequently freeze substituted (AFS2, Leica Microsystems, Vienna, Austria) in anhydrous acetone containing $0.5 \%$ uranyl acetate (prepared from $20 \%$ stock in absolute methanol). After incubation for 42 hours at $-90^{\circ} \mathrm{C}$, the temperature was raised during $24 \mathrm{~h}$ to $-30^{\circ} \mathrm{C}$ and the samples were washed 3 times in anhydrous acetone, infiltrated with increasing concentrations of Lowicryl HM20 resin (4h 10\%, 4h $30 \%$, overnight $60 \%$, 4h $90 \%$, 4h $100 \%$, overnight $100 \%$, 4h $100 \%)$ and polymerized under ultraviolet light. Thin sections (70 nm) were examined in a Tecnai Spirit T12 electron microscope (FEI, Eindhoven, the Netherlands) operating at $120 \mathrm{kV}$. Images were recorded with an Eagle $2 \mathrm{k} \times 2 \mathrm{k}$ CCD camera (FEl).

\section{QUANTIFICATION AND STATISTICAL ANALYSIS}

Statistical details of experiments can be found in the figure legends. Standard Error of Mean (SEM) calculation and Kolmogorov-Smirnov tests were performed using built-in scripts in MATLAB (MathWorks, MA). One-way ANOVA test was performed using GraphPad Prism software.

\section{DATA AND CODE AVAILABILITY}

Raw data supporting the study is provided in Tables S1 and S2, and any other raw data and MATLAB code used for analysis are available from the corresponding authors upon request. 